\title{
Poverty, Stressful Life Events, and Coping Strategies
}

\author{
Joaquina Palomar Lever \\ Universidad Iberoamericana, Mexico, D.F.
}

\begin{abstract}
It was hypothesized that individuals of low socioeconomic status are exposed to a greater number of stressful events and therefore have a higher incidence of psychological disorders. However, the way they interpret, evaluate and cope with these stressful situations may either cause them to maintain, intensify or eliminate their overall stress. Past research indicates that the poorest individuals tend most frequently to falsely minimize or avoid stressful situations, which lowers the probability of resolving their problems. The objective of this study is to discover and compare the situations that have produced a high level of stress in subjects of three different socioeconomic groups over the last three months, as well as the strategies they used to cope, and their perceived effectiveness. The sample included 900 subjects of both sexes living in Mexico City. Among them, 346 were extremely poor, 260 were moderately poor and 312 were not poor. The results indicate that socioeconomic status is related to the frequency with which subjects report certain kinds of stressful situations. It was also found that non-poor subjects use problem-focused coping methods more than the other groups, while the poor use more emotionally-focused coping strategies. This article analyzes the strategies used by each group in each type of stressful situation reported. Keywords: coping, poverty, socioeconomic status, stress, stressful life events
\end{abstract}

Se ha hipotetizado que las personas de los niveles socioeconómicos más bajos están expuestas a un mayor número de eventos estresantes y por tanto presentan mayores índices de trastornos psicológicos; sin embargo, la manera como sienten, evalúan y afrontan las situaciones, permite mantener, intensificar o eliminar la tensión que experimentan. De acuerdo con la literatura los individuos más pobres tienden a minimizar y evadir con mayor frecuencia las situaciones estresantes, lo que hace menos probable resolver de manera satisfactoria los problemas. El objetivo de la presente investigación fue conocer y comparar el tipo de situaciones que sujetos de tres niveles socioeconómicos reportan haberles producido un alto nivel de estrés en los últimos tres meses; así como conocer las estrategias que utilizan para afrontarlos y el nivel de efectividad percibido. La muestra se constituyo de 900 sujetos de ambos sexos, que vivían en la Ciudad de México. De estos 346 eran pobres extremos, 260 pobres moderados y 312 no pobres. Los resultados permitieron observar que el estrato socioeconómico esta relacionado con la frecuencia con la que distintos tipos de situaciones estresantes son reportadas por los individuos. Además, pudo observarse que los no pobres utilizan en mayor medida las estrategias centradas en el problema, mientras que los más pobres las estrategias emocionales. Se analiza el tipo de estrategia utilizada por cada grupo en cada tipo de situación estresante reportada por los individuos. Palabras clave: afrontamiento, pobreza, nivel socioeconómico, estrés, eventos de vida estresantes

Correspondence concerning this article should be addressed to Joaquina Palomar Lever, Universidad Iberoamericana-Ciudad de México, Prol. Paseo de la Reforma 880, 01210 Lomas de Santa Fe, México, D.F. SPhone:. (52) (55) 5950-40-00 - Ext. 4866. Fax. (52) (55) 5950-42-89. E-mail: joaquina.palomar@uia.mx 
For decades, the distribution of psychological illness across different socioeconomic groups has been of interest to researchers. The literature has shown that psychological disorders are more prevalent among those with low-paying jobs, those who have a low level of education and among women.

Authors such as Brown, Ni Bhrol-chain and Harris (1975), and Thoits (1982) have observed that subjects of the lower class are exposed to a greater number of stressful events and situations that cause them emotional suffering compared to upper and middle class subjects. However, economic difference is inadequate in explaining the way in which that stress progresses, which suggests that not only is there a differential distribution of stress across social groups but that the psychological resources necessary to cope with stress are as well. This implies that people of low socioeconomic class have less efficient coping mechanisms and lack the social resources to combat stress.

People are not passive victims of the undesirable events that befall them because the way in which they interpret, evaluate and cope with stressful situations may either cause them to maintain, intensify or eliminate their overall stress. When confronted with stressful situations, people react in a variety of ways to manage it, known as resolution styles or strategies. These psychological tools play a crucial role in the relationship between stress and illness.

According to Lazarus and Folkman, stress resolution refers to the combination of learned behavioral responses that are effective in reducing stress by neutralizing risky, stress-producing situations.

To further approach this theme requires an investigation, first of what constitutes psychological stress, and then of what cognitive processes an individual undergoes during those threatening moments which generate stress.

\section{Stress Theory}

The term "stress" may be defined as suffering and adversity and dates back to the $15^{\text {th }}$ century (Lumsden, 1981, cited in Lazarus, 1993). However, it was not until the $17^{\text {th }}$ century that the term acquired technical significance for the physicist-biologist Robert Hook who was interested in manmade structures such as bridges that were designed to support a certain weight as well as resist the wind, earthquakes and other forces of nature. For the purpose of this study, let us define stress as the relationship between an individual and his or her environment when it is evaluated by the individual as exceeding his or her resources and endangering his or her well-being.

The theory identifies two processes as crucial mediators of the relationship between stress, the individual, his or her environment and long-term consequences: cognitive evaluation and coping.

\section{Cognitive Evaluation}

In the 1950's, Lazarus and his colleagues (Lazarus \& Ericsson, 1952, cited in Lazarus \& Folkman, 1984) discovered that individual differences explain the grade to which events are evaluated as stressful. Though some stimuli represent a clear threat to the individual to such a magnitude that practically anyone would consider them dangerous or harmful, there are individual differences in the extent to which it they are considered stressful, in terms of both their qualitative and quantitative effects. A person's reaction to one such stimulus depends on the novelty of the situation for him or her, on its predictability, and upon the amount of uncertainty it produces.

There are two types of cognitive evaluation: primary and secondary. In the former, the individual evaluates whether or not something of his or hers is at risk and perceives any threat posed to his or herself. A range of personal characteristics such as values, commitments, goals and beliefs about oneself and the world help a person identify the magnitude of the risk to their well-being faced in a given, stressful situation. In the second, the person evaluates the options available to overcome or prevent stress, and to improve the situation. Various coping strategies are evaluated, such as changing the situation, accepting it, seeking more information from which to decide, or reacting impulsively (Folkman, Lazarus, Gruen, \& DeLongis, 1986). The notion that one's coping style be stable is a controversial topic. It has been confirmed that coping is a dynamic process which may vary from one stressful situation to another, which suggests that the development of a single, stable coping style would actually be counterproductive because it would limit the possibilities from which to select an appropriate response to a given set of circumstances. However, other authors maintain that people prefer to use certain coping mechanisms to combat stress which are derived from the dimensions of personality (McCrae, 1982, cited in Carver, Scheier, \& Weintraub, 1989).

Since the mid $20^{\text {th }}$ century, several relevant studies have been carried out on the subject of stress associated with important life events. In such events, objective experiences disorganize or threaten to disorganize the everyday activities of the individual, causing him or her to substantially readapt their behavior (Dohrenwend \& Dohrenwend, 1969; Holmes \& Rahe, 1967). Meyer was one of the first authors to detect the great importance of major life events in the advent of nervous tension and believed that a subject passes through a series of life events that leave important marks, both positive and negative, upon his or her health. At the same time, Holmes and Rahe (1967) created the instrumental Social Readjustment Scale, supported by empirical data, which is used to actually measure the negative events which provoke stress. By conducting a wide poll of subjects, they tried to establish the stress-value that participants attribute to a series of events generally considered to be agents of 
life change. Studies such as that of Holmes and Rahe provide information to the field about individual differences in the way in which people perceive important life events, suggesting that one's perception of an event may be even more significant than the event itself.

On the other hand, several theories exist to respond to the mechanical conception of the individual which emphasize the identification of sources of change in the individual's environment as opposed to identifying changes produced by the individual him or herself. Within this strain the contributions of researchers such as Dohrenwend and Dohrenwend (1978) are found, who consider that the anticipation of a situation is determined by characteristics of the individual while the control of that situation is largely determined by the situation's characteristics or by the nature of the events. These authors include in their model four elements: pre-existing stressors, mediating factors, psychosocial adaptation syndrome and adaptive or non-adaptive responses.

In a dialectic model, development would be seen as a product of middle values clashing with the values of the individual, so external events would effectively contribute to changing the state of the individual over time. Authors such as Reese and Smyer (1983) place life events into the following categories: the context in which the event takes place, the area of functioning affected (biological or psychological in nature? representing a change in the physical, social, cultural or historical environments?), the causes of the event, and the event itself. With these elements in mind, the categories were ultimately considered to be: biological, personal or psychological, environmental or physical and socio-cultural.

One of the most important controversies on the subject has been the challenge of pinpointing that crucial quality of an event which causes it to produce illness or other negative or undesirable aspects of change. Dohrenwend (1973) confirms that the stressful character of an event is that it induces change more than for its sheer undesirability. However, other researchers believe that psychological disorders are more strongly correlated with the undesirable character of the change than with the sum total change the situation demands (Thoits, 1983). The undesirable events experienced by an individual over a period of time have shown a strong association with symptoms of psychological disorder (Samaniego, 2001; Sandler \& Ramsay, 1980).

\section{Coping}

As previously mentioned, this term refers to the cognitive and behavioral forces employed to manage (reduce, minimize, dominate, or tolerate) personal needs and the external demands of one's environment, the latter having been deemed by the individual to exceed his or her resources. Coping has two primary functions: to grapple with the stress-inducing problem at hand and to regulate the emotions it provokes.
According to Folkman and Lazarus (1980), there are two general coping styles. The primary objective of the first, problem-centered, is to resolve the problem or otherwise interrupt the source of stress. The objective of the second, emotionally-centered, is to reduce or manage the emotional stress associated with the situation. Although the majority of stressors elicit both coping strategies, the problem-centered coping predominates when people feel that some constructive action may be taken, while the emotionally-centered response predominates when the person feels that the stressor ought to be resisted. Some emotionally-centered coping involves a denial response, another a positive reinterpretation of the events and in a third, the search for social support. These coping mechanisms differ from each other greatly and may have bearing upon the success of the individual at overcoming the stressor.

Carver, Scheier and Weintraub (1989) demonstrate other ways of coping such as active coping, the process of taking steps to actively improve the circumstances surrounding the stress or at least to minimize its effects. In planning, the individual plans a method of confronting the stressor, including the creation of plans of action and thinking about the necessary steps and the best way to manage the problem. Suppression, on the other hand, is a person's avoidance of competitive activities or channels of competition in order to allow full concentration on the challenge. Restriction is awaiting the appropriate opportunity to act instead of acting preemptively. It is an active strategy in that the behavior is focused on coping with the stressor but it is at once passive in that no action is taken. The search for social support comes into play when the individual is in need of advice, help, information, emotional support, empathy or understanding. Social support is instrumental in determining the style of coping selected because the more social support one receives, the more likely he or she becomes to use active coping methods (Zaldívar, 1996).

Still more coping strategies have arisen from analyses of empirical evidence. One such approach is mental detachment, in which a wide range of behaviors and activities serve to distract the individual from the behavior or goal which with the stressor has interfered (escaping into fantasy, dream, television, etc.). In positive reinterpretation, a positive spin is put on the stressful event; some benefit is found. Denial minimizes the stressful situation by ignoring the stress one feels. It is widely considered that this last strategy only creates additional problems unless the stressor really can be ignored. Denying the reality of an event may allow it to escalate and become more serious than it initially, which makes coping more difficult when it is ultimately forced to occur. (Mattews, Siegel, Kuller, Thompson, \& Varat, 1983, cited in Carver, Scheier, \& Weintraub, 1989).

An individual's coping style is determined by the resources available to him or her in terms of health, physical energy, beliefs, commitments, problem-solving skills, social abilities and social support and material resources. This implies that coping is a task which calls upon a diverse range of abilities. 
The manner in which one copes with problems and everyday stress is a question of great relevance because the situation acceptable resolution of the situation depends upon it and because it impacts how people feel, emotionally, which is related to psychological and social functioning.

\section{Poverty, Stress and Coping}

The majority of the results of the present research has shown evidence that people of the lower class are exposed to a greater number of stressful events and that they show greater emotional suffering than those of the upper class. (Dohrenwend \& Dohrenwend, 1970; Langner \& Michael, 1963, cited in Kessler \& Cleary, 1980). In spite of the fact that a large part of empirical research and theory has focused on this relationship, little is known about the factors surrounding the higher level of emotional suffering of the lower class.

Research on this problem is based almost exclusively on the hypothesis that the greater the exposure to stressful life experiences, the greater the level of suffering in the lower class, and that this emotional suffering has an impact over psychological functioning (Dohrenwend, 1970).

In addition to the hypothesis of the high incidence of stressful events, it has been widely believed that people of the lower class are for one reason or another more sensitive to stress than those of a higher position in society. A study by Kessler and Cleary (1980) demonstrated that while undesirable/stressful life events seem to be more present in the lives of the poor, the uneducated, women, the young and the unmarried, the differential prevalence of those events has little to do with the presence or absence of psychological disorder. According to those authors, it seems that the underserved groups mentioned above are more vulnerable to stressful events and to the tension they incur. In other words, stress associated with important life events has a greater psychological impact on them. Also, the findings suggest that not only is life stress differentially distributed across these groups, but the psychological resources with which to cope with it are differentially distributed as well. These disadvantaged groups have inefficient coping mechanisms and/or have less social support with which to cope with the stress that confronts them more frequently than it does other socioeconomic groups.

Several years ago, Kohn (1968) confirmed that the greater risk of schizophrenia and other psychological disorders among the lower class is related to the fatal combination of genetic predisposition, a stressful life, inflexible coping responses and the socialization that takes place in the culture of poverty.

Generally, researchers have suggested that the interaction between a stressful life and the use of inadequate coping tactics and/or inadequate social support may have a differential impact on the psychological vulnerability of certain socio-demographic groups when exposed to stress. In this light, some researchers consider that coping responses and social support can significantly reduce the psychological impact of stressful events, known as the "depreciation hypothesis" (Thoits, 1982).

In a study carried out by Thoits (1982), it was observed that among women, those who had a lower level of education, lower wages and a lower occupational level were presented with significantly higher levels of stress. Likewise, it was found that women who had higher levels of education and wages also had a larger amount of available social support. Generally speaking, no singular means of social support cushioned the effects of undesirable events. Participation in religious activities reduced the level of stress provoked by health-related events. The number of close friends, the frequency of visits paid to neighbors and the frequency of participation in organizations all had a relative influence on stress surrounding health related events. The author concluded that only certain kinds of social support moderated the impact of certain types of stressful events.

It is generally accepted that the impact of stress on emotional functioning is mediated by both individual and environmental characteristics (Dohrenwend \& Dohrenwend, 1970). It is the individual that assigns meaning to the potentially stressful situation and it is this evaluation which determines whether or not the situation is deemed threatening. Personality characteristics, then, act to either multiply or reduce the impact of stress, according to subjective evaluation (Lazarus, Averill, \& Opton, 1974, cited in Kessler \& Cleary, 1980).

High self-esteem and the perception of personal control are elements that seem to reduce the perception of a threat. These are conceptualized as "social competence," the individual's general level of psychological functioning as seen in their ability to confront the stress associated with everyday life (Johnson \& Sarason, 1979; Kaplan, 1970).

To summarize, it has been confirmed that stressful life experiences have greater psychologically damaging effects on individuals of the lower class. This is because people of that class are at a disadvantage in their access to both psychological and social resources. With respect to psychological resources, it is known that feelings of personal value and control over one's environment are positively related with social status (Pearlin \& Schooler, 1978; Rosenberg \& Pearlin, 1978), and it is believed that other psychological tools are related to coping (Dohrenwend \& Dohrenwend, 1970; Kohn, 1976; 1977). As for social resources, it is known that the poor are at a disadvantage not only in terms of objective resources, such as money and political power (Antonovsky, 1979), but also in their comparatively limited access to social relationships that provide them with support and to stable relations with their communities (Dohrenwend \& Dohrenwend, 1970; Liem \& Liem, 1978).

The present study has various objectives: (a) to identify and compare the types of situations which subjects of three socioeconomic levels (extremely poor, moderately poor and not poor) report as having produced a high level of stress in the last three months; (b) to identify the type of coping 
strategies that subjects manifest in order to contend with the stressful situations they reported (in other words, what they did to resolve the problem when it presented itself), how they felt about using those strategies and how the strategies helped them resolve difficult situations; And (c) Finally, a relationship was sought between the type of stressful situation reported, the coping strategy used and the extent to which that strategy was considered to have resolved the situation or problem.

\section{Method}

The present study is a cross study, comparative and ex post facto and was carried out on subjects of three socioeconomic groups: extremely poor, moderately poor and not poor.

\section{Participants}

The sample used for the study consisted of 900 subjects from three socioeconomic groups: extremely poor, moderately poor and not poor. There were 450 female subjects (50\%) and the other 450 were male. Also, half of the subjects were young (between 20 and 35 years old) while the other half were older (between 36 and 50 years old).

The sample selection was stratified, in which several different neighborhoods from 16 political delegations of the Federal District were selected at random and 16 of the 22 unified cities of the State of Mexico (the sum of which is known as "Mexico City"), making sure that the same number of neighborhoods was chosen from each city, as well as from each socioeconomic strata. Once the neighborhoods were selected, visits were paid to subjects' homes. These visits began to establish a climate of trust, explaining the objectives of the study and asking questions of an economic nature (particularly those related to the minimum amount needed to support a family for one month) to assure that the subjects met the criteria surrounding the socioeconomic construct known as the "poverty line," which allowed them to be classified as extremely poor, moderately poor or not poor. The selection of the homes visited was not randomized.

The method of establishing the poverty line was based on the CEPAL-INEGI model (Economic Commission for Latin America and the National Institute of Statistics, Geography and Data Processing, 1993). This method consisted of: a) defining a person's basic needs to live, b) defining the minimum amount of food and household items needed to fulfill those essential needs, c) calculating the monthly cost of that minimum amount and d) classifying as extremely poor the homes that have a monthly income below that amount. The minimum food and goods required for a family to survive for a month, as proposed by CEPAL-INEGI (1993) includes the following nutritional groups: (a) cereal and cereal products, (b) meat, (c) milk and milk products, (d) eggs, (e) oils and fats, (f) tubers and roots, (g) legumes, (h) vegetables, (i) fruits, (j) sugars, (k) processed foods, (l) drinks. The monthly cost of these basic needs at the time of the data collection (July, 2000) was \$265.83 American dollars for a family of 4.4, on average. Given the aforementioned cost, a home with a monthly income at or below $\$ 265.83$ American dollars was considered to live in extreme poverty.

Along those lines, CEPAL-INEGI (1993) quantified moderate poverty by doubling the extreme poverty line. Thus, a home living in moderate poverty has a monthly food consumption which falls above the extreme poverty line but is less than its double, greater than $\$ 265.83$ and less than $\$ 531.66$.

\section{Instruments}

To gather data, an ex profeso instrument was designed, which had two open-ended questions categorized at some time after data collection, two Likert-style questions and one multiple choice question. The open-ended questions were the following:

1. Describe a situation that occurred in the last three months that worried you or made you feel a lot of stress.

2. What did you do to try to resolve that situation?

The following were the Likert-style questions:

3. How did you feel when you (the action you took in response)? (very bad, bad, regular, good, very good)

4. How much did your action help to resolve the situation? (not at all, a little, a lot, completely)

The following item was the multiple choice question:

5. What feelings did the situation provoke in you? (anxiety, sadness, desperation, courage, disappointment, fear)

\section{Statistical Analysis}

The answers to the open-ended questions were codified and reduced into a few response categories to facilitate the quantitative analysis. Also, the data collected from the item dealing with subjects' responses to the situations that caused them stress was analyzed using a Chi-square test and then analyzed and classified using as a base the classification of coping strategies proposed by Aldwin and Revenson (1987). Next, frequencies and percentages of the variables were taken and contingency tables were made to identify any association between the variables studied and belonging to a socioeconomic group (by using Chi-square and Cramer's V). Standardized residuals were obtained in order to understand particularly which categories are related with statistical significance.

Next, between groups differences were investigated according to the type of feelings the stressful situations produced using a Chi-square analysis and the Cramer V test (when dealing with nominal variables). Also, two simple analyses of variance and Tukey's post-hoc test of multiple comparisons were done to see if there was a statistically significant difference in the perceived effectiveness of the coping strategy employed and the way in which the subjects felt after using it. Finally, in order to know if there was a relationship between the type of 
stressful situation reported, the coping strategy used and the extent to which the situation or problem was considered to be resolved, a multiple correspondence analysis was performed, which more easily located in a perceptual plane any differences and similarities in their answers.

\section{Results}

In order to fulfill the desired objectives, first, subjects' responses to the open-ended questions were categorized. The answers reported by subjects on the question about the most stressful types of situations they had experienced in the previous three months were grouped into nine categories: (a) health (b) education, (c) family, (d) economic, (e) work, (f) emotional, (g) social, (h) addictions, and (i) death (of a friend or relative). Meanwhile, each category had various subcategories. Table 1 shows the frequencies and percentages surrounding subjects' answers to this question.

First of all, it should be noted that the situations that most stressed subjects across the entire sample were those related to health (of one's children, parents, relatives, one's own health and that of one's spouse), those in the academic sphere (low academic achievement, behavioral problems, worries for one's children's studies), family problems (with a significant other, with children, with other relatives, family separation and lack of attention paid to one's children), economic problems (covering basic necessities, paying for education, buying groceries, paying rent and to covering medical expenses), problems or situations related to work (lack of work, conflicts at work, excess of work and pressure at work), emotional problems (depression, low self-esteem, anxiety, stress), natural disasters and the death of friends or relatives. Observing Table 1, one might notice that family problems are reported by the total sample as the most stressful and of these, those related with one's significant other; health problems follow, particularly those having to do with subjects' children. The standardized residuals shown in Table 1-A show that the moderately poor group is the most stressed by health problems as compared to the not poor. Furthermore, the not poor group is more stressed than the extremely poor by the subjects of education, family and emotional well-being. Lastly, economic problems are particularly worrisome to the poor, especially when compared to the not poor, $\chi^{2}=89.780$, $p=.000$, Cramer's $V=.225, p=.000$.

As for the answers subjects gave regarding what actions they took to resolve the situation (coping), these were classified according to the categories proposed by Aldwin and Revenson: (a) direct or problem-centered (finding a solution and carrying it out), (b) emotional (courage, frustration, sadness, anxiety, fear, worry, resignation and desperation), (c) support-seeking, (d) self-blame, (e) denial or reduction (to deny or minimize the stressor, to apply religious beliefs to the situation or indifference), and (f) nothing (hoping that the situation resolves itself without taking any action), as shown in Table 2 (Aldwin \& Revenson, 1987).
The frequencies in this table show that the three groups, with great frequency, use direct coping strategies in comparison with any other type of strategy. However, all three groups also utilize emotional strategies (and with greatest frequency among the extremely poor group).

The standardized residuals show that the not poor group uses direct coping strategies with greater frequency than the extremely poor and that the inverse is true with regards to emotional strategies. Also, the not poor use supportseeking strategies less than the other groups and the extremely poor exhibit the tactic of self-blame more frequently than the other groups, $\chi^{2}=34.604, p=.000$, Cramer's $V=.140, p=.000$.

Next, the frequencies with which subjects used different coping mechanisms and the stressful situations in which they did so were obtained (see Tables 3 through 5). As was previously mentioned, some categories were combined in the contingency tables in order to avoid cells with a frequency of less than 5 cases.

\section{Health-related Situations}

The stressful situations referred to imply a bad state of health in the subject or a close relative and are primarily associated with use of direct coping strategies in the case of the extremely and moderately poor. The moderately poor group uses direct coping more than other strategies in problems related to health. Extremely poor, $\chi^{2}=29.692, p$ $=.001$, Cramer's $V=.212, p=.001 ;$ moderately poor, $\chi^{2}$ $=18.278, p=.050$, Cramer's $V=.192, p=.050$; not poor, $\chi^{2}=13.671, p=.189$, Cramer's $V=.150, p=.089$.

\section{Education-related Situations}

The analysis of standardized residuals indicates that among the extremely poor, direct coping strategies are associated with stressful situations pertaining to education. In the other two groups no significant associations were observed between stressful situations and the use of a particular coping strategy. Furthermore, the moderately poor use other strategies (emotional support, self-blame, denial or minimizing and doing nothing) to cope with this type of situation less often than the other two groups.

\section{Family Situations}

According to the standardized residuals in the tables, it may be observed that among the extremely poor the use of emotional coping strategies is significantly lower in stressful, family situations.

\section{Economic Situations}

In the case of economic stress situations, the only standardized residuals observed indicate significant associations 
Table 1

Stressful Events Reported by the Three Socioeconomic Groups Studied Categories and Subcategories

\begin{tabular}{|c|c|c|c|c|c|c|c|c|}
\hline \multirow{3}{*}{\multicolumn{2}{|c|}{ STRESSFUL SITUATIONS }} & \multicolumn{7}{|c|}{ SOCIOECONOMIC GROUPS } \\
\hline & & \multicolumn{2}{|c|}{ Extreme Poverty } & \multicolumn{2}{|c|}{ Moderate Poverty } & \multicolumn{2}{|c|}{ No Poverty } & \multirow[b]{2}{*}{ Total } \\
\hline & & $N$ & $\%$ & $N$ & $\%$ & $N$ & $\%$ & \\
\hline \multicolumn{9}{|c|}{ 1. HEALTH } \\
\hline 1.1 & Children's health & 36 & 10.9 & 27 & 10.8 & 12 & 3.9 & 75 \\
\hline 1.2 & Parents' health & 15 & 4.5 & 19 & 7.6 & 14 & 4.6 & 48 \\
\hline 1.3 & Other relatives' health & 4 & 1.2 & 4 & 1.6 & 2 & .7 & 10 \\
\hline 1.4 & Own health & 11 & 3.3 & 20 & 8 & 12 & 3.9 & 43 \\
\hline \multirow[t]{2}{*}{1.5} & Spouse's health & 7 & 2.1 & 7 & 2.8 & 4 & 1.3 & 18 \\
\hline & TOTAL & 73 & 22 & 77 & 30.8 & 44 & 14.4 & 194 \\
\hline \multicolumn{9}{|c|}{ 2. EDUCATION } \\
\hline 2.1 & Low academic achievement & 4 & 1.2 & 4 & 1.6 & 6 & 2 & 14 \\
\hline 2.2 & Behavioral problems & 4 & 1.2 & 2 & .8 & 6 & 2 & 12 \\
\hline 2.3 & Worries about one's children's education & 1 & .3 & 6 & 2.4 & 7 & 2.3 & 14 \\
\hline \multirow[t]{2}{*}{2.4} & Worries about one's own education & 4 & 1.2 & 3 & 1.2 & 6 & 2 & 13 \\
\hline & TOTAL & 13 & 3.9 & 15 & 6 & 25 & 8.3 & 53 \\
\hline \multicolumn{9}{|c|}{ 3. FAMILY } \\
\hline 3.1 & Conflict with significant other & 23 & 6.9 & 19 & 7.6 & 38 & 12.4 & 80 \\
\hline 3.2 & Conflict with children & 19 & 5.7 & 10 & 4 & 23 & 7.5 & 52 \\
\hline 3.3 & Worries for other relatives & 11 & 3.3 & 17 & 6.8 & 19 & 6.2 & 47 \\
\hline 3.4 & Family separation & 9 & 2.7 & 4 & 1.6 & 11 & 3.6 & 24 \\
\hline \multirow[t]{2}{*}{3.5} & Lack of attention paid to the children & 1 & .3 & 5 & 2 & 15 & 4.9 & 21 \\
\hline & TOTAL & 63 & 18.9 & 55 & 22 & 106 & 34.6 & 224 \\
\hline \multicolumn{9}{|c|}{ 4. ECONOMIC } \\
\hline 4.1 & Lack of money to cover basic needs & 52 & 15.7 & 23 & 9.2 & 22 & 7.2 & 97 \\
\hline 4.2 & Lack of money for education & 15 & 4.5 & 10 & 4 & 1 & .3 & 26 \\
\hline 4.3 & Lack of money for rent & 18 & 5.4 & 1 & .4 & 6 & 2 & 25 \\
\hline \multirow[t]{2}{*}{4.4} & Lack of money to cover health problems & 11 & 3.3 & 2 & .8 & 0 & 0 & 13 \\
\hline & TOTAL & 96 & 28.9 & 36 & 14.4 & 29 & 9.5 & 161 \\
\hline \multicolumn{9}{|c|}{ 5. WORK } \\
\hline 5.1 & Lack of work & 27 & 8.2 & 12 & 4.8 & 21 & 6.9 & 60 \\
\hline 5.2 & Conflicts at work & 3 & .9 & 3 & 1.2 & 10 & 3.3 & 16 \\
\hline 5.3 & Excessive amount of work & 4 & 1.2 & 4 & 1.6 & 5 & 1.6 & 13 \\
\hline \multirow[t]{2}{*}{5.4} & Pressure at work & 3 & .9 & 8 & 3.2 & 12 & 3.9 & 23 \\
\hline & TOTAL & 37 & 11.2 & 27 & 10.8 & 48 & 15.7 & 112 \\
\hline \multicolumn{9}{|c|}{ 6. EMOTIONAL } \\
\hline 6.1 & Depresion, low self-esteem & 4 & 1.2 & 2 & .8 & 6 & 2 & 12 \\
\hline 6.2 & Anxiety about a pregnancy & 9 & 2.7 & 9 & 3.6 & 7 & 2.3 & 25 \\
\hline \multirow[t]{2}{*}{6.3} & Stress & 0 & 0 & 4 & 1.6 & 12 & 3.9 & 16 \\
\hline & TOTAL & 13 & 3.9 & 15 & 6 & 25 & 8.2 & 53 \\
\hline \multicolumn{2}{|c|}{ 7. NATURAL DISASTERS } & 16 & 4.8 & 9 & 3.6 & 19 & 6.2 & 44 \\
\hline \multicolumn{2}{|c|}{ 8. ADDICTIONS } & 4 & 1.2 & 5 & 2 & 1 & .3 & 10 \\
\hline \multicolumn{2}{|c|}{ 9. DEATHS } & 16 & 4.8 & 11 & 4.4 & 9 & 2.9 & 36 \\
\hline & TOTAL & 331 & $100 \%$ & 250 & $100 \%$ & 306 & $100 \%$ & 887 \\
\hline
\end{tabular}


Table 1-A

Stressful Events Reported by the Three Socioeconomic Groups Studied

\begin{tabular}{|c|c|c|c|c|c|}
\hline \multirow{2}{*}{\multicolumn{2}{|c|}{ STRESSFUL SITUATIONS }} & \multicolumn{4}{|c|}{ SOCIOECONOMIC GROUPS } \\
\hline & & \multirow{2}{*}{$\frac{\text { Extremely Poor }}{73}$} & \multirow{2}{*}{$\begin{array}{c}\text { Moderately Poor } \\
77\end{array}$} & \multirow{2}{*}{$\frac{\text { Not Poor }}{44}$} & \multirow{2}{*}{$\begin{array}{r}\text { Total } \\
194\end{array}$} \\
\hline Health & Frequency & & & & \\
\hline & $\%$ situation & $37.6 \%$ & $39.7 \%$ & $22.7 \%$ & $100 \%$ \\
\hline & $\%$ group & $22.1 \%$ & $30.8 \%$ & $14.4 \%$ & $21.9 \%$ \\
\hline & $\%$ total & $8.2 \%$ & $8.7 \%$ & $5.0 \%$ & $21.9 \%$ \\
\hline & Corrected residuals & .1 & 4.0 & -3.9 & \\
\hline \multirow[t]{5}{*}{ Education } & Frequency & 13 & 15 & 25 & 53 \\
\hline & $\%$ situation & $24.5 \%$ & $28.3 \%$ & $47.2 \%$ & $100 \%$ \\
\hline & $\%$ group & $3.9 \%$ & $6.0 \%$ & $8.2 \%$ & $6.0 \%$ \\
\hline & $\%$ total & $1.5 \%$ & $1.7 \%$ & $2.8 \%$ & $6.0 \%$ \\
\hline & Corrected residuals & -2.0 & .0 & 2.0 & \\
\hline \multirow[t]{5}{*}{ Family } & Frequency & 63 & 55 & 106 & 224 \\
\hline & $\%$ situation & $28.1 \%$ & $24.6 \%$ & $47.3 \%$ & $100 \%$ \\
\hline & $\%$ group & $19.0 \%$ & $22.0 \%$ & $34.6 \%$ & $25.3 \%$ \\
\hline & $\%$ total & $7.1 \%$ & $6.2 \%$ & $12.0 \%$ & $25.3 \%$ \\
\hline & Corrected residuals & -3.3 & -1.4 & 4.7 & \\
\hline \multirow[t]{5}{*}{ Economic } & Frequency & 96 & 36 & 29 & 161 \\
\hline & $\%$ situation & $59.6 \%$ & $22.4 \%$ & $18.0 \%$ & $100 \%$ \\
\hline & $\%$ group & $29.0 \%$ & $14.4 \%$ & $9.5 \%$ & $18.2 \%$ \\
\hline & $\%$ total & $10.8 \%$ & $4.1 \%$ & $3.3 \%$ & $18.2 \%$ \\
\hline & Corrected residuals & 6.5 & -1.8 & -4.9 & \\
\hline \multirow[t]{5}{*}{ Work } & Frequency & 37 & 27 & 48 & 112 \\
\hline & $\%$ situation & $33.0 \%$ & $24.1 \%$ & $42.9 \%$ & $100 \%$ \\
\hline & $\%$ group & $11.2 \%$ & $10.8 \%$ & $15.7 \%$ & $12.6 \%$ \\
\hline & $\%$ total & $4.2 \%$ & $3.0 \%$ & $5.4 \%$ & $12.6 \%$ \\
\hline & Corrected residuals & -1.0 & -1.0 & 2.0 & \\
\hline \multirow[t]{5}{*}{ Emotional } & Frequency & 13 & 15 & 25 & 53 \\
\hline & $\%$ situation & $24.5 \%$ & $28.3 \%$ & $47.2 \%$ & $100 \%$ \\
\hline & $\%$ group & $3.9 \%$ & $6.0 \%$ & $8.2 \%$ & $6.0 \%$ \\
\hline & $\%$ total & $1.5 \%$ & $1.7 \%$ & $2.8 \%$ & $6.0 \%$ \\
\hline & Corrected residuals & -2.0 & .0 & 2.0 & \\
\hline \multirow[t]{5}{*}{ Natural Disasters } & Frequency & 16 & 9 & 19 & 44 \\
\hline & $\%$ situation & $36.4 \%$ & $20.5 \%$ & $43.2 \%$ & $100 \%$ \\
\hline & $\%$ group & $4.8 \%$ & $3.6 \%$ & $6.2 \%$ & $5.0 \%$ \\
\hline & $\%$ total & $1.8 \%$ & $1.0 \%$ & $2.1 \%$ & $5.0 \%$ \\
\hline & Corrected residuals & -.1 & -1.2 & 1.2 & \\
\hline \multirow[t]{5}{*}{ Addictions } & Frequency & 4 & 5 & 1 & 10 \\
\hline & $\%$ situation & $40.0 \%$ & $50.0 \%$ & $10.0 \%$ & $100 \%$ \\
\hline & $\%$ group & $1.2 \%$ & $2.0 \%$ & $.3 \%$ & $1.1 \%$ \\
\hline & $\%$ total & $.5 \%$ & $.6 \%$ & $.1 \%$ & $1.1 \%$ \\
\hline & Corrected residuals & .2 & 1.5 & -1.6 & \\
\hline \multirow[t]{5}{*}{ Deaths } & Frequency & 16 & 11 & 9 & 36 \\
\hline & $\%$ situation & $44.4 \%$ & $30.6 \%$ & $25.0 \%$ & $100 \%$ \\
\hline & $\%$ group & $4.8 \%$ & $4.4 \%$ & $2.9 \%$ & $4.1 \%$ \\
\hline & $\%$ total & $1.8 \%$ & $1.2 \%$ & $1.0 \%$ & $4.1 \%$ \\
\hline & Corrected residuals & .9 & .3 & -1.2 & \\
\hline \multirow[t]{4}{*}{ Total } & Frequency & 331 & 250 & 306 & 887 \\
\hline & $\%$ situation & $37.3 \%$ & $28.2 \%$ & $34.5 \%$ & $100 \%$ \\
\hline & $\%$ group & $100 \%$ & $100 \%$ & $100 \%$ & $100 \%$ \\
\hline & $\%$ total & $37.3 \%$ & $28.2 \%$ & $34.5 \%$ & $100 \%$ \\
\hline
\end{tabular}

Note. $\chi^{2}=89.780, p=.000$, Cramer's $V=.225, P=.000$. 
Table 2

Coping Strategies Used by the Three Socioeconomic Groups

\begin{tabular}{|c|c|c|c|c|c|}
\hline \multirow{2}{*}{\multicolumn{2}{|c|}{ COPING STRATEGIES }} & \multicolumn{4}{|c|}{ SOCIOECONOMIC GROUPS } \\
\hline & & \multirow{2}{*}{$\frac{\text { Extremely Poor }}{183}$} & \multirow{2}{*}{$\begin{array}{c}\text { Moderately Poor } \\
170\end{array}$} & \multirow{2}{*}{$\begin{array}{r}\text { Not Poor } \\
221\end{array}$} & \multirow{2}{*}{$\begin{array}{r}\text { Total } \\
574\end{array}$} \\
\hline Direct & Frequency & & & & \\
\hline & $\%$ situation & $31.9 \%$ & $29.6 \%$ & $38.5 \%$ & $100 \%$ \\
\hline & $\%$ group & $55.3 \%$ & $68.0 \%$ & $72.5 \%$ & $64.8 \%$ \\
\hline & $\%$ total & $20.7 \%$ & $19.2 \%$ & $24.9 \%$ & $64.8 \%$ \\
\hline & Corrected Residuals & -4.6 & 1.3 & 3.5 & \\
\hline \multirow{5}{*}{ Emotional } & Frequency & 51 & 28 & 26 & 105 \\
\hline & $\%$ situation & $48.6 \%$ & $26.7 \%$ & $24.8 \%$ & $100 \%$ \\
\hline & $\%$ group & $15.4 \%$ & $11.2 \%$ & $8.5 \%$ & $11.9 \%$ \\
\hline & $\%$ total & $5.8 \%$ & $3.2 \%$ & $2.9 \%$ & $11.9 \%$ \\
\hline & Corrected Residuals & 2.5 & -.4 & -2.2 & \\
\hline Support - & Frequency & 18 & 12 & 6 & 36 \\
\hline \multirow[t]{4}{*}{ Seeking } & $\%$ situation & $50.0 \%$ & $33.3 \%$ & $16.7 \%$ & $100 \%$ \\
\hline & $\%$ group & $5.4 \%$ & $4.8 \%$ & $2.0 \%$ & $4.1 \%$ \\
\hline & $\%$ total & $2.0 \%$ & $1.4 \%$ & $.7 \%$ & $4.1 \%$ \\
\hline & Corrected Residuals & 1.6 & .7 & -2.3 & \\
\hline \multirow[t]{5}{*}{ Self-Blame } & Frequency & 12 & 1 & 2 & 15 \\
\hline & $\%$ situation & $80.0 \%$ & $6.7 \%$ & $13.3 \%$ & $100 \%$ \\
\hline & $\%$ group & $3.6 \%$ & $.4 \%$ & $.7 \%$ & $1.7 \%$ \\
\hline & $\%$ total & $1.4 \%$ & $.1 \%$ & $.2 \%$ & $1.7 \%$ \\
\hline & Corrected Residuals & 3.4 & -1.9 & -1.7 & \\
\hline Denial or & Frequency & 37 & 17 & 25 & 79 \\
\hline \multirow{4}{*}{ Reductionism } & $\%$ situation & $46.8 \%$ & $21.5 \%$ & $31.6 \%$ & $100 \%$ \\
\hline & $\%$ group & $11.2 \%$ & $6.8 \%$ & $8.2 \%$ & $8.9 \%$ \\
\hline & $\%$ total & $4.2 \%$ & $1.9 \%$ & $2.8 \%$ & $8.9 \%$ \\
\hline & Corrected Residuals & 1.8 & -1.4 & -.5 & \\
\hline \multirow[t]{5}{*}{ Nothing } & Frequency & 30 & 22 & 25 & 77 \\
\hline & $\%$ situation & $39.0 \%$ & $28.6 \%$ & $32.5 \%$ & $100 \%$ \\
\hline & $\%$ group & $9.1 \%$ & $8.8 \%$ & $8.2 \%$ & $8.7 \%$ \\
\hline & $\%$ total & $3.4 \%$ & $2.5 \%$ & $2.8 \%$ & $8.7 \%$ \\
\hline & Corrected Residuals & .3 & .1 & -.4 & \\
\hline \multirow[t]{4}{*}{ Total } & Frequency & 331 & 250 & 305 & 886 \\
\hline & $\%$ situation & $37.4 \%$ & $28.2 \%$ & $34.4 \%$ & $100 \%$ \\
\hline & $\%$ group & $100 \%$ & $100 \%$ & $100 \%$ & $100 \%$ \\
\hline & $\%$ total & $37.4 \%$ & $28.2 \%$ & $34.4 \%$ & $100 \%$ \\
\hline
\end{tabular}

Note. $\chi^{2}=34.604, p=.000$, Cramer's $V=.140, p=.000$.

with the extremely poor group. In particular, it is apparent that subjects in this group utilize a diverse array of coping strategies (seeking emotional support, self-blame, denial and minimizing) to deal with this type of situation or problem, and concurrently their use of direct strategies has a low probability of occurrence. In the other two groups there was no statistically significant association.

\section{Work Situations}

According to the frequency with which coping strategies were mentioned by subjects, all the groups primarily utilize direct coping strategies in work situations. However, the standardized residuals indicate that there is no significant association between the use of any type of coping strategy and work situations.

Other Types of Stressful Situations (Natural Disasters, Addictions, Deaths, and Emotional Problems)

Into this category primarily fall emotional situations that participants experience such as depression, anxiety and stress. Also included in this group are natural disasters, addictions 
Table 3

Use of Coping Strategies of the Extremely Poor in Different Types of Stressful Situations: Frequencies and Percentages

\begin{tabular}{|c|c|c|c|c|c|}
\hline \multirow{2}{*}{\multicolumn{2}{|c|}{ STRESSFUL SITUATIONS }} & \multicolumn{4}{|c|}{ COPING STRATEGIES } \\
\hline & & \multirow{2}{*}{$\frac{\text { Direct or Active }}{48}$} & \multirow{2}{*}{$\begin{array}{c}\text { Emotional } \\
10\end{array}$} & \multirow{2}{*}{$\begin{array}{c}\text { Other** } \\
15\end{array}$} & \multirow{2}{*}{$\begin{array}{r}\text { Total } \\
73\end{array}$} \\
\hline Health & Frequency & & & & \\
\hline & $\%$ of situation & $65.8 \%$ & $13.7 \%$ & $20.5 \%$ & $100 \%$ \\
\hline & $\%$ of strategy & $26.2 \%$ & $19.6 \%$ & $15.6 \%$ & $22.1 \%$ \\
\hline & $\%$ of total & $14.5 \%$ & $3.0 \%$ & $4.5 \%$ & $22.1 \%$ \\
\hline & Corrected Residuals & 2.0 & -.5 & -1.8 & \\
\hline \multirow[t]{5}{*}{ Education } & Frequency & 10 & 1 & 1 & 12 \\
\hline & $\%$ of situation & $83.3 \%$ & $8.3 \%$ & $8.3 \%$ & $100 \%$ \\
\hline & $\%$ of strategy & $5.5 \%$ & $2.0 \%$ & $1.0 \%$ & $3.6 \%$ \\
\hline & $\%$ of total & $3.0 \%$ & $.3 \%$ & $.3 \%$ & $3.6 \%$ \\
\hline & Corrected Residuals & 2.0 & -.7 & -1.6 & \\
\hline \multirow[t]{5}{*}{ Family } & Frequency & 35 & 4 & 24 & 63 \\
\hline & $\%$ of situation & $55.6 \%$ & $6.3 \%$ & $38.1 \%$ & $100 \%$ \\
\hline & $\%$ of strategy & $19.1 \%$ & $7.8 \%$ & $25.0 \%$ & $19.1 \%$ \\
\hline & $\%$ of total & $10.6 \%$ & $1.2 \%$ & $7.3 \%$ & $19.1 \%$ \\
\hline & Corrected Residuals & .0 & -2.2 & 1.7 & \\
\hline \multirow[t]{5}{*}{ Economic } & Frequency & 43 & 15 & 38 & 96 \\
\hline & $\%$ of situation & $44.8 \%$ & $15.6 \%$ & $39.6 \%$ & $100 \%$ \\
\hline & $\%$ of strategy & $23.5 \%$ & $29.4 \%$ & $39.6 \%$ & $29.1 \%$ \\
\hline & $\%$ of total & $13.0 \%$ & $4.5 \%$ & $11.5 \%$ & $29.1 \%$ \\
\hline & Corrected Residuals & -2.5 & .1 & 2.7 & \\
\hline \multirow[t]{5}{*}{ Work } & Frequency & 25 & 6 & 6 & 37 \\
\hline & $\%$ of situation & $67.6 \%$ & $16.2 \%$ & $16.2 \%$ & $100 \%$ \\
\hline & $\%$ of strategy & $13.7 \%$ & $11.8 \%$ & $6.3 \%$ & $11.2 \%$ \\
\hline & $\%$ of total & $7.6 \%$ & $1.8 \%$ & $1.8 \%$ & $11.2 \%$ \\
\hline & Corrected Residuals & 1.6 & .1 & -1.8 & \\
\hline \multirow[t]{5}{*}{ Other* } & Frequency & 22 & 15 & 12 & 49 \\
\hline & $\%$ of situation & $44.9 \%$ & $30.6 \%$ & $24.5 \%$ & $100 \%$ \\
\hline & $\%$ of strategy & $12.0 \%$ & $29.4 \%$ & $12.5 \%$ & $14.8 \%$ \\
\hline & $\%$ of total & $6.7 \%$ & $4.5 \%$ & $3.6 \%$ & $14.8 \%$ \\
\hline & Corrected Residuals & -1.6 & 3.2 & -.8 & \\
\hline \multirow[t]{5}{*}{ Total } & Frequency & 183 & 51 & 96 & 330 \\
\hline & $\%$ of situation & $55.5 \%$ & $15.5 \%$ & $29.1 \%$ & $100 \%$ \\
\hline & $\%$ of strategy & $100 \%$ & $100 \%$ & $100 \%$ & $100 \%$ \\
\hline & $\%$ of total & $55.5 \%$ & $15.5 \%$ & $29.1 \%$ & $100 \%$ \\
\hline & $\%$ total & $37.4 \%$ & $28.2 \%$ & $34.4 \%$ & $100 \%$ \\
\hline
\end{tabular}

Note. *emotional situations, natural disasters, addictions and/or deaths.

** emotional support, self-blame, denial or reductionism and nothing.

$\chi^{2}=29.692, p=.001$, Cramer's $V=.212, p=.001$.

and the deaths of loved ones. Tables 3, 4 and 5 show that the extremely poor primarily use emotional strategies while the moderately and the not poor utilize other strategies, in other words, very diverse strategies (emotional support, selfblame, denial and minimizing) to cope with this type of stressful situation.

Next, Tables 6, 7 and 8 show the frequencies and percentages corresponding to subjects' answers to questions about the type of feelings the stressful situation provoked in them as well as the way in which they felt after using the coping mechanism, and how much it helped resolve the situation. Table 6 shows the results of a Chi-square and a Cramer's $V$ test, as well as the standardized residuals that describe which feelings generated by the stressful situation were significantly associated with which groups. Meanwhile, Tables 7A and 8A show the results of an analysis of variance carried out to determine whether there were statistically significant differences between the socioeconomic groups 
Table 4

Use of Coping Strategies of the Moderately Poor in Different Types of Stressful Situations: Frequencies and Percentages

\begin{tabular}{|c|c|c|c|c|c|}
\hline \multirow{2}{*}{\multicolumn{2}{|c|}{ STRESSFUL SITUATIONS }} & \multicolumn{4}{|c|}{ COPING STRATEGIES } \\
\hline & & \multirow{2}{*}{$\frac{\text { Direct or Active }}{60}$} & \multirow{2}{*}{$\frac{\text { Emotional }}{7}$} & \multirow{2}{*}{$\begin{array}{c}\text { Other** } \\
10\end{array}$} & \multirow{2}{*}{$\begin{array}{r}\text { Total } \\
77\end{array}$} \\
\hline Health & Frequency & & & & \\
\hline & $\%$ of situation & $77.9 \%$ & $9.1 \%$ & $13.0 \%$ & $100 \%$ \\
\hline & $\%$ of strategy & $35.5 \%$ & $25.0 \%$ & $19.2 \%$ & $30.9 \%$ \\
\hline & $\%$ of total & $24.1 \%$ & $2.8 \%$ & $4.0 \%$ & $30.9 \%$ \\
\hline & Corrected Residuals & 2.3 & -.7 & -2.1 & \\
\hline \multirow[t]{5}{*}{ Education } & Frequency & 13 & 2 & 0 & 15 \\
\hline & $\%$ of situation & $86.7 \%$ & $13.3 \%$ & $.0 \%$ & $100 \%$ \\
\hline & $\%$ of strategy & $7.7 \%$ & $7.1 \%$ & $.0 \%$ & $6.0 \%$ \\
\hline & $\%$ of total & $5.2 \%$ & $.8 \%$ & $.0 \%$ & $6.0 \%$ \\
\hline & Corrected Residuals & 1.6 & .3 & -2.1 & \\
\hline \multirow[t]{5}{*}{ Family } & Frequency & 36 & 7 & 11 & 54 \\
\hline & $\%$ of situation & $66.7 \%$ & $13.0 \%$ & $20.4 \%$ & $100 \%$ \\
\hline & $\%$ of strategy & $21.3 \%$ & $25.0 \%$ & $21.2 \%$ & $21.7 \%$ \\
\hline & $\%$ of total & $14.5 \%$ & $2.8 \%$ & $4.4 \%$ & $21.7 \%$ \\
\hline & Corrected Residuals & -.2 & .5 & -.1 & \\
\hline \multirow[t]{5}{*}{ Economic } & Frequency & 20 & 5 & 11 & 36 \\
\hline & $\%$ of situation & $55.6 \%$ & $13.9 \%$ & $30.6 \%$ & $100 \%$ \\
\hline & $\%$ of strategy & $11.8 \%$ & $17.9 \%$ & $21.2 \%$ & $14.5 \%$ \\
\hline & $\%$ of total & $8.0 \%$ & $2.0 \%$ & $4.4 \%$ & $14.5 \%$ \\
\hline & Corrected Residuals & -1.7 & .5 & 1.5 & \\
\hline \multirow[t]{5}{*}{ Work } & Frequency & 20 & 1 & 6 & 27 \\
\hline & $\%$ of situation & $74.1 \%$ & $3.7 \%$ & $22.2 \%$ & $100 \%$ \\
\hline & $\%$ of strategy & $11.8 \%$ & $3.6 \%$ & $11.5 \%$ & $10.8 \%$ \\
\hline & $\%$ of total & $8.0 \%$ & $.4 \%$ & $2.4 \%$ & $10.8 \%$ \\
\hline & Corrected Residuals & .7 & -1.3 & .2 & \\
\hline \multirow[t]{5}{*}{ Other* } & Frequency & 20 & 6 & 14 & 40 \\
\hline & $\%$ of situation & $50.0 \%$ & $15.0 \%$ & $35.0 \%$ & $100 \%$ \\
\hline & $\%$ of strategy & $11.8 \%$ & $21.4 \%$ & $26.9 \%$ & $16.1 \%$ \\
\hline & $\%$ of total & $8.0 \%$ & $2.4 \%$ & $5.6 \%$ & $16.1 \%$ \\
\hline & Corrected Residuals & -2.6 & .8 & 2.4 & \\
\hline \multirow[t]{4}{*}{ Total } & Frequency & 169 & 28 & 52 & 249 \\
\hline & $\%$ of situation & $67.9 \%$ & $11.2 \%$ & $20.9 \%$ & $100 \%$ \\
\hline & $\%$ of strategy & $100 \%$ & $100 \%$ & $100 \%$ & $100 \%$ \\
\hline & $\%$ of total & $67.9 \%$ & $11.2 \%$ & $20.9 \%$ & $100 \%$ \\
\hline
\end{tabular}

Note. *emotional situations, natural disasters, addictions and/or deaths.

$* *$ emotional support, self-blame, denial or reductionism and nothing.

$\chi^{2}=18.278, p=.050$, Cramer's V $=.192, p=.050$.

in the way that the subjects felt after using their coping strategies and the perception of which strategy used helped to resolve the situation.

First of all, it is important to note that statistically significant differences were found between socioeconomic groups with respect to the feelings generated by the stressful situations with which they were presented, $\chi^{2}=29.538, p$ $=.003$, Cramer's $V=.129, p=.003$.

According to the standardized residuals in Table 6, evidently for the poor, the most pervasive feeling they experience when presented with a situation that stresses them is desperation, as opposed to the not poor, who would more frequently feel anxiety.

On the other hand, Table 7 demonstrates that the extremely poor report feeling worse than the other two groups after using their respective coping strategies. It is the not poor who report feeling better, $F=4.129, p=.016$. Lastly, when asked how much they considered that the stressful situation had been resolved by use of the coping mechanism (see Table 8), statistically significant differences were observed between the extremely poor and the not poor, the former perceiving their coping strategies as less useful at confronting stressful 
Table 5

Use of Coping Strategies of the Not Poor in Different Types of Stressful Situations: Frequencies and Percentages

\begin{tabular}{|c|c|c|c|c|c|}
\hline \multirow{2}{*}{\multicolumn{2}{|c|}{ STRESSFUL SITUATIONS }} & \multicolumn{4}{|c|}{ COPING STRATEGIES } \\
\hline & & \multirow{2}{*}{$\frac{\text { Direct or Active }}{36}$} & \multirow{2}{*}{$\frac{\text { Emotional }}{3}$} & \multirow{2}{*}{$\begin{array}{r}\text { Other** } \\
5\end{array}$} & \multirow{2}{*}{$\begin{array}{r}\text { Total } \\
44\end{array}$} \\
\hline Health & Frequency & & & & \\
\hline & $\%$ situation & $81.8 \%$ & $6.8 \%$ & $11.4 \%$ & $100 \%$ \\
\hline & $\%$ strategy & $16.4 \%$ & $11.5 \%$ & $8.6 \%$ & $14.5 \%$ \\
\hline & $\%$ total & $11.8 \%$ & $1.0 \%$ & $1.6 \%$ & $14.5 \%$ \\
\hline & Corrected Residuals & 1.5 & -.4 & -1.4 & \\
\hline \multirow[t]{5}{*}{ Education } & Frequency & 17 & 4 & 4 & 25 \\
\hline & $\%$ situation & $68.0 \%$ & $16.0 \%$ & $16.0 \%$ & $100 \%$ \\
\hline & $\%$ strategy & $7.7 \%$ & $15.4 \%$ & $6.9 \%$ & $8.2 \%$ \\
\hline & $\%$ total & $5.6 \%$ & $1.3 \%$ & $1.3 \%$ & $8.2 \%$ \\
\hline & Corrected Residuals & -.5 & 1.4 & -.4 & \\
\hline \multirow[t]{5}{*}{ Family } & Frequency & 79 & 9 & 17 & 105 \\
\hline & $\%$ situation & $75.2 \%$ & $8.6 \%$ & $16.2 \%$ & $100 \%$ \\
\hline & $\%$ strategy & $35.9 \%$ & $34.6 \%$ & $29.3 \%$ & $34.5 \%$ \\
\hline & $\%$ total & $26.0 \%$ & $3.0 \%$ & $5.6 \%$ & $34.5 \%$ \\
\hline & Corrected Residuals & .8 & .0 & -.9 & \\
\hline \multirow[t]{5}{*}{ Economic } & Frequency & 22 & 1 & 5 & 28 \\
\hline & $\%$ situation & $78.6 \%$ & $3.6 \%$ & $17.9 \%$ & $100 \%$ \\
\hline & $\%$ strategy & $10.0 \%$ & $3.8 \%$ & $8.6 \%$ & $9.2 \%$ \\
\hline & $\%$ total & $7.2 \%$ & $.3 \%$ & $1.6 \%$ & $9.2 \%$ \\
\hline & Corrected Residuals & .8 & -1.0 & -.2 & \\
\hline \multirow[t]{5}{*}{ Work } & Frequency & 33 & 6 & 9 & 48 \\
\hline & $\%$ situation & $68.8 \%$ & $12.5 \%$ & $18.8 \%$ & $100 \%$ \\
\hline & $\%$ strategy & $15.0 \%$ & $23.1 \%$ & $15.5 \%$ & $15.8 \%$ \\
\hline & $\%$ total & $10.9 \%$ & $2.0 \%$ & $3.0 \%$ & $15.8 \%$ \\
\hline & Corrected Residuals & -.6 & 1.1 & -.1 & \\
\hline \multirow[t]{5}{*}{ Other* } & Frequency & 33 & 3 & 18 & 54 \\
\hline & $\%$ situation & $61.1 \%$ & $5.6 \%$ & $33.3 \%$ & $100 \%$ \\
\hline & $\%$ strategy & $15.0 \%$ & $11.5 \%$ & $31.0 \%$ & $17.8 \%$ \\
\hline & $\%$ total & $10.9 \%$ & $1.0 \%$ & $5.9 \%$ & $17.8 \%$ \\
\hline & Corrected Residuals & -2.0 & -.9 & 2.9 & \\
\hline \multirow[t]{4}{*}{ Total } & Frequency & 220 & 26 & 58 & 304 \\
\hline & $\%$ situation & $72.4 \%$ & $8.6 \%$ & $19.1 \%$ & $100 \%$ \\
\hline & $\%$ strategy & $100 \%$ & $100 \%$ & $100 \%$ & $100 \%$ \\
\hline & $\%$ total & $72.4 \%$ & $8.6 \%$ & $19.1 \%$ & $100 \%$ \\
\hline
\end{tabular}

Note. *emotional situations, natural disasters, addictions and/or deaths.

**emotional support, self-blame, denial or reductionism and nothing.

$\chi^{2}=13.671, p=.189$, Cramer'sV $=.150, p=.189$.

situations than the latter $(F=4.127 ; p=.016)$.

In order to know if there was some relationship between the type of stressful situation reported by subjects, the strategies utilized and the perception of their effectiveness, an analysis of correspondence was performed ${ }^{1}$ in order to more easily locate in the perceptual plane any differences or similarities between their answers.

The analysis was done separately for each of the three socioeconomic groups (extremely poor, moderately poor and not poor). A description of the results follows.

\footnotetext{
1 The purpose of the analysis of multiple correspondences, also known as an analysis of homogeneity, is to find the best, optimal assessments, in other words, to separate the categories to the maximum possible. This means that the items within each category are very similar while the objects of other categories are as different and distant as possible.
} 
Table 6

Feelings Generated by the Stressful Situation

\begin{tabular}{|c|c|c|c|c|c|}
\hline \multirow{2}{*}{\multicolumn{2}{|c|}{$\begin{array}{l}\text { FEELINGS GENERATED BY } \\
\text { THE STRESSFUL SITUATION }\end{array}$}} & \multicolumn{4}{|c|}{ SOCIOECONOMIC GROUPS } \\
\hline & & \multirow{2}{*}{$\frac{\text { Extremely Poor }}{58}$} & \multirow{2}{*}{$\frac{\text { Moderately Poor }}{68}$} & \multirow{2}{*}{$\frac{\text { Not Poor }}{91}$} & \multirow{2}{*}{$\begin{array}{r}\text { Total } \\
217\end{array}$} \\
\hline Anxiety & Frequency & & & & \\
\hline & $\%$ feelings & $26.7 \%$ & $31.3 \%$ & $41.9 \%$ & $100 \%$ \\
\hline & $\%$ group & $17.5 \%$ & $27.1 \%$ & $29.8 \%$ & $24.4 \%$ \\
\hline & $\%$ total & $6.5 \%$ & $7.7 \%$ & $10.2 \%$ & $24.4 \%$ \\
\hline & Corrected Residuals & -3.7 & 1.2 & 2.7 & \\
\hline \multirow[t]{5}{*}{ Sadness } & Frequency & 63 & 59 & 65 & 187 \\
\hline & $\%$ feelings & $33.7 \%$ & $31.6 \%$ & $34.8 \%$ & $100 \%$ \\
\hline & $\%$ group & $19.0 \%$ & $23.5 \%$ & $21.3 \%$ & $21.1 \%$ \\
\hline & $\%$ total & $7.1 \%$ & $6.6 \%$ & $7.3 \%$ & $21.1 \%$ \\
\hline & Corrected Residuals & -1.2 & 1.1 & .1 & \\
\hline \multirow[t]{5}{*}{ Desperation } & Frequency & 99 & 52 & 51 & 202 \\
\hline & $\%$ feelings & $49.0 \%$ & $25.7 \%$ & $25.2 \%$ & $100 \%$ \\
\hline & $\%$ group & $29.8 \%$ & $20.7 \%$ & $16.7 \%$ & $22.7 \%$ \\
\hline & $\%$ total & $11.1 \%$ & $5.9 \%$ & $5.7 \%$ & $22.7 \%$ \\
\hline & Corrected Residuals & 3.9 & -.9 & -3.1 & \\
\hline \multirow[t]{5}{*}{ Courage } & Frequency & 53 & 35 & 51 & 139 \\
\hline & $\%$ feelings & $38.1 \%$ & $25.2 \%$ & $36.7 \%$ & $100 \%$ \\
\hline & $\%$ group & $16.0 \%$ & $13.9 \%$ & $16.7 \%$ & $15.7 \%$ \\
\hline & $\%$ total & $6.0 \%$ & $3.9 \%$ & $5.7 \%$ & $15.7 \%$ \\
\hline & Corrected Residuals & .2 & -.9 & .6 & \\
\hline \multirow[t]{5}{*}{ Deception } & Frequency & 10 & 8 & 10 & 28 \\
\hline & $\%$ feelings & $35.7 \%$ & $28.6 \%$ & $35.7 \%$ & $100 \%$ \\
\hline & $\%$ group & $3.0 \%$ & $3.2 \%$ & $3.3 \%$ & $3.2 \%$ \\
\hline & $\%$ total & $1.1 \%$ & $.9 \%$ & $1.1 \%$ & $3.2 \%$ \\
\hline & Corrected Residuals & -.2 & .0 & .2 & \\
\hline \multirow[t]{5}{*}{ Fear } & Frequency & 42 & 22 & 27 & 91 \\
\hline & $\%$ feelings & $46.2 \%$ & $24.2 \%$ & $29.7 \%$ & $100 \%$ \\
\hline & $\%$ group & $12.7 \%$ & $8.8 \%$ & $8.9 \%$ & $10.2 \%$ \\
\hline & $\%$ total & $4.7 \%$ & $2.5 \%$ & $3.0 \%$ & $10.2 \%$ \\
\hline & Corrected Residuals & 1.8 & -.9 & -1.0 & \\
\hline \multirow[t]{5}{*}{ Other } & Frequency & 7 & 7 & 10 & 24 \\
\hline & $\%$ feelings & $29.2 \%$ & $29.2 \%$ & $41.7 \%$ & $100 \%$ \\
\hline & $\%$ group & $2.1 \%$ & $2.8 \%$ & $3.3 \%$ & $2.7 \%$ \\
\hline & $\%$ total & $.8 \%$ & $.8 \%$ & $1.1 \%$ & $2.7 \%$ \\
\hline & Corrected Residuals & -.8 & .1 & .8 & \\
\hline \multirow[t]{4}{*}{ Total } & Frequency & 332 & 251 & 305 & 888 \\
\hline & $\%$ feelings & $37.4 \%$ & $28.3 \%$ & $34.3 \%$ & $100 \%$ \\
\hline & $\%$ group & $100 \%$ & $100 \%$ & $100 \%$ & $100 \%$ \\
\hline & $\%$ total & $37.4 \%$ & $28.3 \%$ & $34.3 \%$ & $100 \%$ \\
\hline
\end{tabular}

$\chi^{2}=29.538, p=.003$, Cramer's $V=.129, p=.003$. 
Table 7

How Subjects Felt upon Using the Coping Strategy

\begin{tabular}{|c|c|c|c|c|}
\hline \multirow{2}{*}{ FEELINGS } & \multicolumn{4}{|c|}{ SOCIOECONOMIC STATUS } \\
\hline & Extremely Poor & Moderately Poor & Not Poor & Total \\
\hline \multirow[t]{2}{*}{ Very Bad } & 76 & 40 & 23 & 139 \\
\hline & $8.6 \%$ & $4.5 \%$ & $2.6 \%$ & $15.7 \%$ \\
\hline \multirow[t]{2}{*}{$\mathrm{Bad}$} & 52 & 35 & 19 & 106 \\
\hline & $5.9 \%$ & $4.0 \%$ & $2.1 \%$ & $12.0 \%$ \\
\hline \multirow[t]{2}{*}{ Normal } & 77 & 75 & 108 & 260 \\
\hline & $8.7 \%$ & $8.5 \%$ & $12.2 \%$ & $29.4 \%$ \\
\hline \multirow[t]{2}{*}{ Good } & 90 & 82 & 133 & 305 \\
\hline & $10.2 \%$ & $9.3 \%$ & $15.0 \%$ & $34.5 \%$ \\
\hline \multirow[t]{2}{*}{ Very Good } & 35 & 20 & 19 & 74 \\
\hline & $4.0 \%$ & $2.3 \%$ & $2.1 \%$ & $8.4 \%$ \\
\hline \multirow[t]{2}{*}{ TOTAL } & 330 & 252 & 302 & 884 \\
\hline & $37.3 \%$ & $28.5 \%$ & $34.2 \%$ & $100 \%$ \\
\hline
\end{tabular}

Table 7A

ANOVA Comparing the Groups in the Way they Felt after using their Coping Strategies

\begin{tabular}{lccccc}
\hline Comparisons & $S S$ & $d f$ & $M S$ & $F$ & Significance \\
\hline Between-groups & 23.159 & 2 & 11.580 & 4.129 & .016 \\
Within groups & 2482.182 & 885 & 2.805 & & \\
Total & 2505.341 & 887 & & \\
\hline
\end{tabular}

Note. *According to Tukey's post-hoc test, statistically significant differences were found between the extremely poor and moderately poor groups and between the extremely poor and not poor groups.

Table 8

Extent to which the Strategy Resolved the Situation

\begin{tabular}{|c|c|c|c|c|}
\hline \multirow{2}{*}{ SUCCESS } & \multicolumn{4}{|c|}{ SOCIOECONOMIC STATUS } \\
\hline & Extremely Poor & Moderately Poor & Not Poor & Total \\
\hline \multirow[t]{2}{*}{ Not at all } & 63 & 41 & 33 & 137 \\
\hline & $7.1 \%$ & $4.6 \%$ & $3.7 \%$ & $15.4 \%$ \\
\hline \multirow[t]{2}{*}{ A little } & 83 & 70 & 70 & 223 \\
\hline & $9.4 \%$ & $7.9 \%$ & $7.9 \%$ & $25.1 \%$ \\
\hline \multirow[t]{2}{*}{ A lot } & 141 & 92 & 155 & 388 \\
\hline & $15.9 \%$ & $10.4 \%$ & $17.5 \%$ & $43.7 \%$ \\
\hline \multirow[t]{2}{*}{ Entirely } & 43 & 49 & 47 & 139 \\
\hline & $4.8 \%$ & $5.5 \%$ & $5.3 \%$ & $15.7 \%$ \\
\hline \multirow[t]{2}{*}{ TOTAL } & 330 & 252 & 305 & 887 \\
\hline & $37.2 \%$ & $28.4 \%$ & $34.4 \%$ & $100 \%$ \\
\hline
\end{tabular}

Table 8A

ANOVA comparing the Groups in their Perception of which Strategy Helped to Resolve the Situation

\begin{tabular}{lccccc}
\hline Comparisons & $S S$ & $d f$ & $M S$ & $F$ & Significance \\
\hline Between- groups & 7.081 & 2 & 3.541 & 4.127 & .016 \\
Within-groups & 758.427 & 884 & .858 & \\
Total & 2505.341 & 887 & & \\
\hline
\end{tabular}

Note. *According to Tukey's post-hoc test, statistically significant differences were found between the extremely poor and not poor groups. 


\section{The Extremely Poor}

The consistency between the two dimensions ranged from .47 to .41 , respectively, with Eigenvalues greater than 1. According to Figure 1, first of all, it may be observed that health and work situations are related with direct coping strategies and with a high level of perceived effectiveness of the strategies. When the stress-generating problems are of an economic nature, coping responses tend to be avoidant. In emotional, as well as family and economic problems, no particular coping strategies are associated with perceived effectiveness. The first two variables (type of stressful situation and coping strategy) weigh heavily upon the second dimension while the effectiveness of the strategy variable weighs more heavily upon the first dimension (see Figure 2).

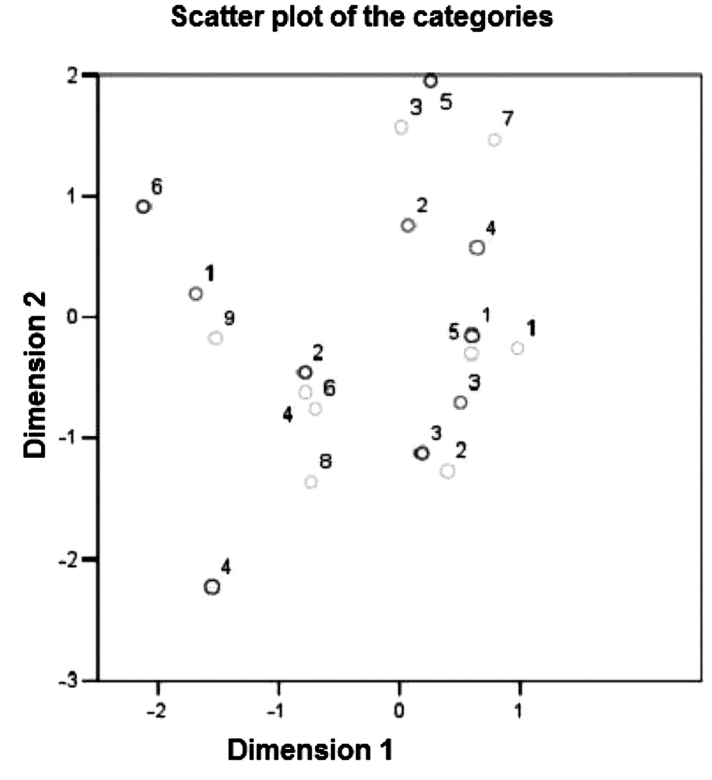

Symmetrical normalization

Figure 1. Extremely poor.

\section{Discriminant scores}

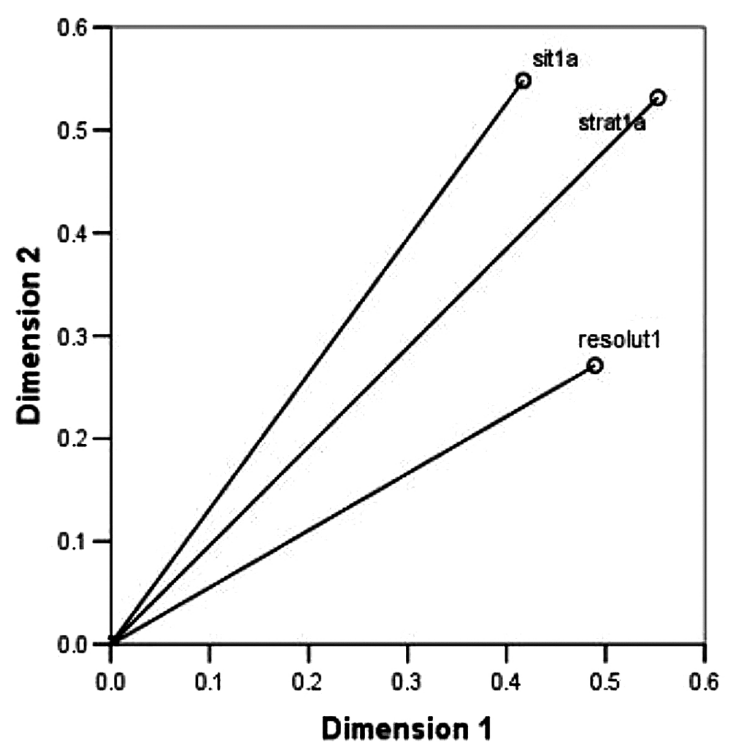

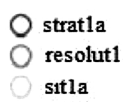

\section{EXTREME LY POOR}

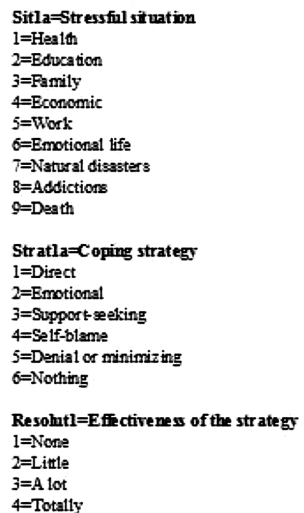

Symmetrical normalization

\begin{tabular}{|l|r|r|r|}
\multicolumn{4}{c}{ Discriminant scores } \\
\cline { 2 - 3 } \multicolumn{1}{c|}{} & \multicolumn{1}{|c|}{ Dimension } & \multicolumn{1}{c|}{. } \\
\cline { 2 - 4 } \multicolumn{1}{c|}{} & \multicolumn{1}{c|}{ Mean } \\
\hline sit1a & .417 & .548 & .483 \\
strat1a & .553 & .53 & .542 \\
resolut1 & .489 & .271 & 380 \\
Active total & 1.459 & 1.351 & 1.405 \\
\hline
\end{tabular}

Figure 2. Extremely poor. 
The Moderately Poor

An analysis of the moderately poor group shows that the consistency of the two dimensions is slightly higher in this group (.61 and .51), with Eigenvalues greater than 1 . The perceptual map shows a greater aggregation of points, which indicates that stressful health situations are related to direct coping strategies (see Figure 3). The first two variables (stressful situations and coping strategies) weigh more heavily over the second dimension, while the effectiveness of the strategy is more influential over the first (see Figure 4).

Scatter plot of the categories

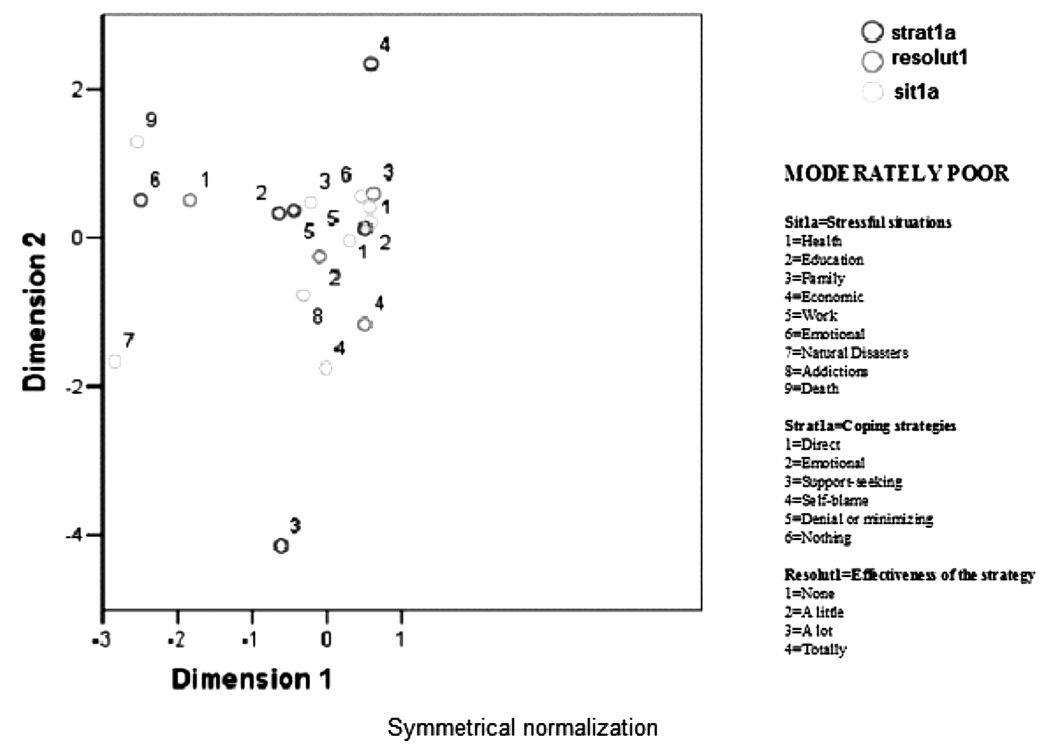

Figure 3. Moderately poor.

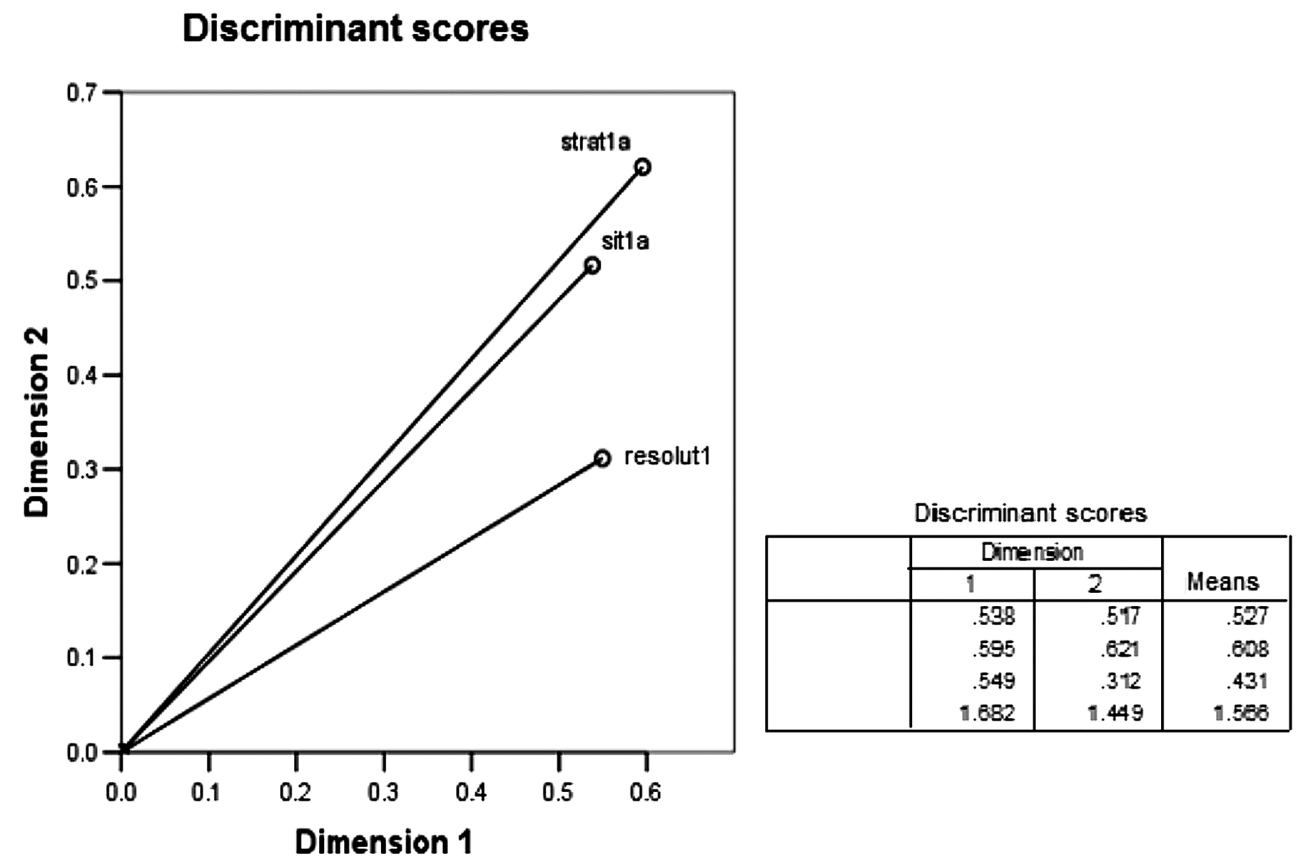

Symmetrical normalization

Figure 4. Moderately poor. 


\section{The Not Poor}

The consistency of the dimensions ranges from .68-.40. Also, the Eigenvalues are greater than 1. Regarding the map, it appears that for health events, direct strategies are both utilized by the not poor and are perceived as effective. Events in education are widely perceived as able to be solved although no point related to the preferred strategy in this type of situation is found on the map. Finally, subjects consider that when they "do nothing," the possibilities of resolving the problematic situations are scarce (see Figure 5). The coping strategies variable ended up being more influenced by the second dimension, while the other two were more influenced by the first (see Figure 6).

\section{Scatter plot of the categories}
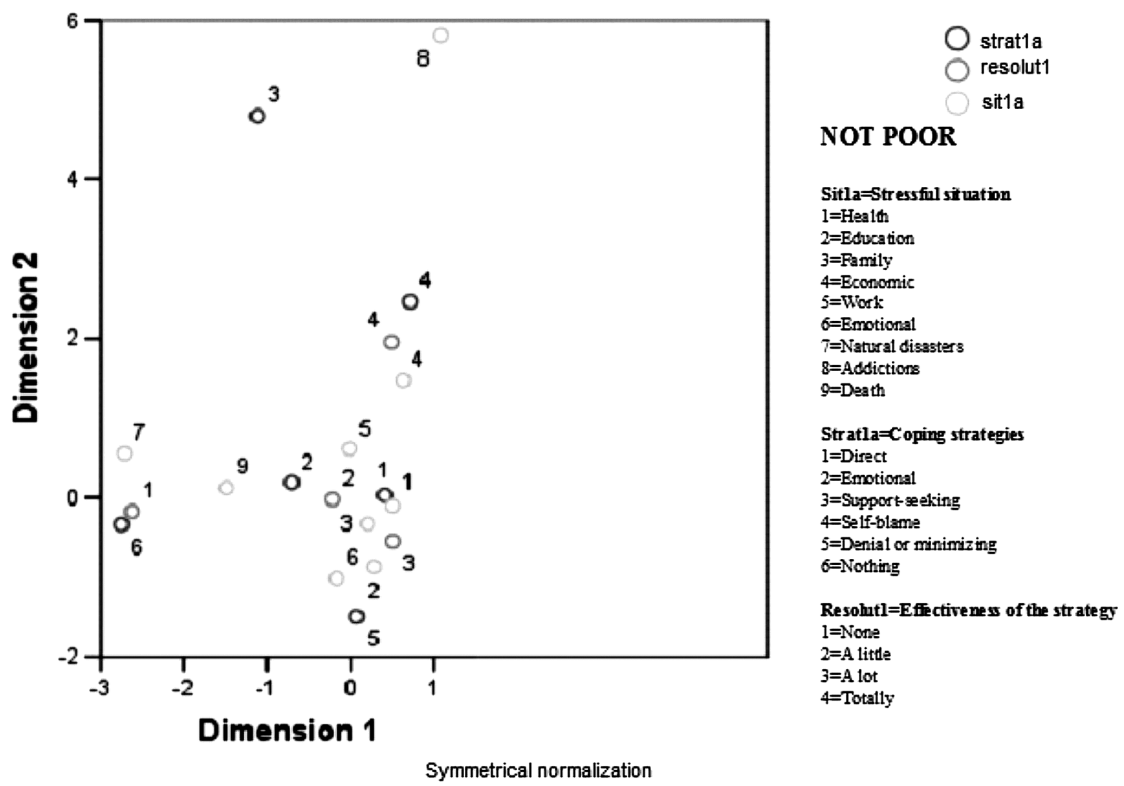

Figure 5. Not poor.

\section{Discriminant scores}

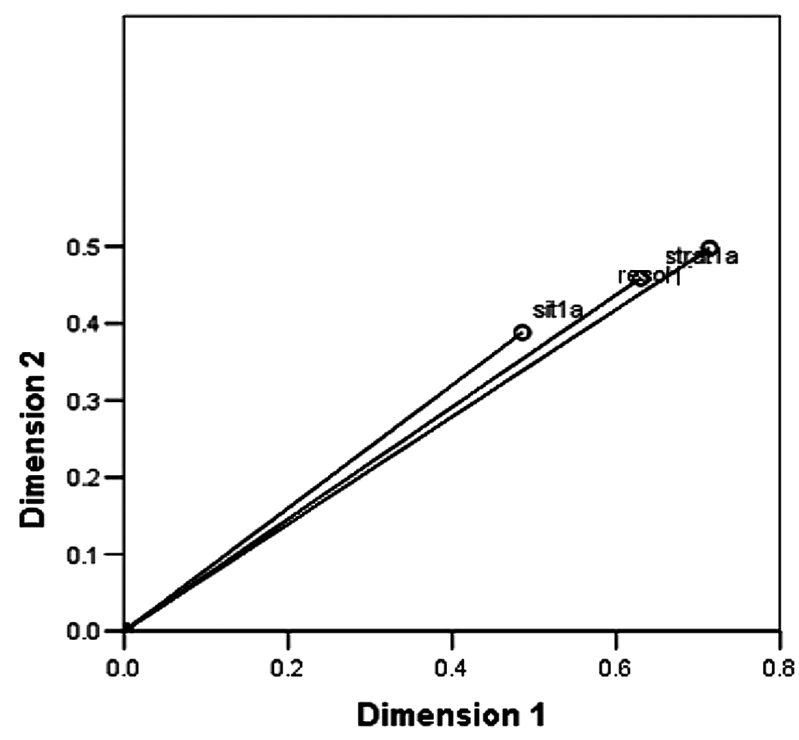

\begin{tabular}{|l|r|r|r|}
\hline \multicolumn{4}{c|}{ Discriminant scores } \\
\cline { 2 - 3 } \multicolumn{1}{c|}{} & \multicolumn{2}{c|}{ Dimension } & \multirow{2}{*}{ Mean } \\
\cline { 2 - 3 } & 1 & .388 & .437 \\
sit1 a & .488 & .459 & .544 \\
strat1a & .630 & .459 & .606 \\
resolut1 & .714 & .497 & 1.587 \\
\hline Active total & 1.830 & 1.344 & 1.58 \\
\hline
\end{tabular}

Symmetrical normalization

Figure 6. Not poor. 


\section{Discussion}

The literature on this subject reports that the poorest subjects are more widely exposed to a greater number of stressful events and experience greater emotional suffering. Though the present study did not attempt to provide evidence that there exists a differential in the degree of exposure to stressful events according to socioeconomic level, it did demonstrate that the situations reported by subjects as being most stressful and the ways of coping with them differ between the three groups.

First of all, it should be noted that the findings reveal that the problems most stressful to subjects are of a diverse character, and are independent of the socioeconomic group to which they pertain. As could be expected, the extremely poor group was that which suffered most from economic problems (lack of money to cover basic needs and other costs such as education, rent, etc.), while the moderately poor report being more stressed by health problems and the not poor group worried more often about family, educational and emotional situations.

The difference between groups in the number of times each of the stressful situations was mentioned reflects upon the limitations that the economic condition imposes on subjects. In the case of the poor, the worries are more related to survival, while the not poor more often reported problems of an affective or interactive type. The fact that there are severe problems associated with poverty that are not mentioned by the poor themselves is important to note. For example, they do not report problems feeding or housing themselves but rather refer to those types of problems as a consequence of a lack of money while other problems that tend to be frequent in this population such as alcoholism, substance abuse and domestic abuse, are not even mentioned.

As for the case of the not poor, the problems or situations to which they allude are little or not related to their economic situations and are more centered on interpersonal and emotional matters (family conflicts, education and emotional problems such as anxiety and depression).

With respect to coping strategies, the fact that all three groups report using mostly direct coping strategies calls the reader's attention, given that generally, literature on the subject points to a tendency among the poorest individuals to minimize and avoid stressful situations, which causes their problems to go unresolved in a satisfactory and reasonable way (Aldwin \& Revenson, 1987; Greenlee \& Lantz, 1993). Although all three groups confirm that they use direct coping strategies frequently, there are important differences depending on the socioeconomic to which the subjects pertain; the not poor group uses them more frequently than the extremely poor group. As for emotional strategies, it has been shown that they are most recurrent among the poor subjects, in comparison with the not poor group. With respect to support-seeking strategies, the not poor group tends to use them the least, in contrast with selfblame, which is most frequently used among the extremely poor.

\section{Coping Strategies used by the Extremely Poor}

It is important to emphasize that even if the extremely poor group shows a higher frequency than the other two groups in their use of evasive or emotional strategies (for example emotional coping and self-blame), it is also certain that they more often use direct strategies -not in comparison with the other two groups, but in comparison with their use of the other strategies.

These findings are promising in the sense that even when subjects of this group have had few educational and social opportunities, they still have the tools to help themselves leave their precarious condition behind. According to literature in the field, direct strategies of coping with stress are associated with better mental health, and low levels of stress, anxiety and depression (Greenle \& Lantz, 1993), a high level of perceived efficiency of the strategies and a strong motivation for achievement, which are all indispensable elements of escaping poverty.

Another interesting aspect observed in the data analysis is that the groups in the study cope in different ways according to the type of situation that presents itself, confirming Folkman's thesis (Folkman et al., 1986) that coping is a dynamic process that changes from one stressful situation to another.

There are some situations in which the extremely poor cope primarily with direct strategies, like those related to education and health. In these types of situations, any other strategy is rarely mentioned. However, in other situations (emotional problems, addictions and deaths), subjects in this group widely use emotional strategies and in family problems, they are the group that uses direct coping strategies the least.

It must be noted that the majority of the use of supportseeking and self-blame strategies were declared by the extremely poor (18 out of 36 and 12 out of 15 , respectively). Both types of strategies were used primarily in economic situations, which again reiterates that in trying to satisfy basic needs, this group may deploy alternative coping strategies, including the use of social networks of support. Though previous research has confirmed that economically disadvantaged groups have less access to social support to cope with the stress to which they are so frequently exposed (see for example Dohrenwend \& Dohrenwend, 1070; Liem \& Liem, 1978), the results of the present study show that it is precisely they who most often look to that tool to resolve economic problems, or at least to reduce their level of stress.

Also, it is worth noting the high probability that the situations in which a large percentage of the extremely poor turn to evasive coping strategies are those which are difficult 
to handle or resolve in a clear, particular way. In this study, these stressful or problematic situations were economic. There are no known studies which refer specifically to the influence of subjects' living in poverty, nor that refer to conflict situations of this nature, nor which investigate the impact that an adequate handling of those conflict situations would have on the possibility of remaining in (versus escaping) poverty.

\section{Coping Strategies of the Moderately Poor}

Authors such as Thoits (1982) have found that the lower the socioeconomic status of the subjects, the greater the use of emotional and evasive coping strategies and the lower the use of direct strategies. This study partially confirms those results in that the moderately poor tend to utilize emotional strategies less than the extremely poor. However, the not poor report that in some stressful situations, that is not how it works. For example, it has been demonstrated that in educational and family situations, subjects in the moderately poor group more often use emotional and evasive strategies than the extremely poor. Also, in those same situations (educational and family) as well as in work-related situations, they tend to use this tool less in comparison with the not poor, which was unexpected (see for example Kohn, 1977). On the contrary, and in accordance with previous findings reported (see Lomnitz, 1998), it is the extremely poor who most often resort to strategies such as seeking support to cope with stress.

With respect to direct coping strategies, some inconsistencies were observed, such as the fact that the extremely poor more often use this type of strategy than the moderately poor (although the standardized residuals are not statistically significant).

Also consider that in health-related situations the use of direct strategies was higher among the extremely poor than among the not poor (although the standardized residuals of the second group do not show a significant association) and in economic, work-related and other situations (addictions, natural disasters, deaths, etc.), the frequency of use of direct strategies among the moderately poor is reported as being lower than among the extremely poor. It is peculiar that the moderately poor exhibit this type of behavior, given that they would seem to share certain characteristics with the poorest individuals and others with the not poor.

The reasons are unknown for which the moderately poor exhibit such distinct behavior in their use of coping strategies depending on the type of stressful situation at hand, being at times more similar to the extremely poor and at others more like the not poor. Along these lines, consider that no information is available with respect to whether the poverty of this group is permanent (their families have been poor for many generations) or temporary (this generation or the previous one experienced either a social ascent or descent). This aspect is important because each social stratum impresses upon its members certain values, beliefs, behaviors and attitudes and develops certain competencies and abilities. Thus, individuals who experience a change in social status, a social mobility, have behaviors and attitudes distinct from others of their social status (and visa versa; in other words, individuals who exhibit behaviors different from those of their social stratum will have a greater possibility of ascending or descending from their social stratum (Balán, Blowing, \& Jelin, 1973; Biblarz \& Raftery, 1993; Thomson, McLanahan, \& Curtin, 1992). Furthermore, when an individual or group has experienced social mobility, and especially when it was recent, they come to share certain characteristics with their new stratum, which may explain the behavior of the moderately poor group.

\section{Coping Strategies of the Not Poor}

When global frequencies are taken into account (without considering the type of stressful situation), the not poor, in greatest proportion, uses direct coping strategies and least uses emotional strategies.

Stressful situations related to the spheres of family and work are the most frequent among this group. Table 2 shows that this group copes directly the most often of the three socioeconomic groups, and emotionally and through supportseeking the least. The results in Table 5 show that there was no relationship between the specific type of problem (for example health, education, etc.) and the type of coping employed. It would be beneficial to deepen the investigation of the types of strategies used by people who are not poor across different contexts, in order to provide additional data in this area.

\section{Feelings Generated by a Stressful Situation, the Use of a Strategy and Perceived Effectiveness}

It is well-known that when an individual is confronted with a very threatening situation, a number of reactions are activated for a number of reasons: first of all, to inform the subject about the danger presented by the situation (cognitive as well as emotional) and to set in motion defense mechanisms for the situation and/or resolution strategies.

The feelings generated by a threatening situation are important because, like motors, they either put into action or inhibit positive behaviors that favor equilibrium. In this way, it is important to observe that in this study, when faced with stress, the least poor primarily felt anxiety, the most poor felt desperation and the moderately poor felt both anxiety and sadness (although the standardized residuals in this group were not significant). The objective of this study was not to understand to what extent these emotions were related to the use of certain coping strategies, nor if they 
were associated with the perceived effectiveness of the strategy used. However, those questions emphasize that the type of emotions experienced by the subjects, as well as the type of coping strategies used, appear to be related to the socioeconomic status of the subjects. Also, the extremely poor showed greater variability in the way they felt after using their coping strategies in comparison with the less poor, the majority of whom reported feeling normal or fine afterwards.

The Relationship between the Type of Stressful Situation, Coping Strategies Used and their Perceived Effectiveness

The analysis of correlation allows one to discern that the relationship between the type of stressful situation, the coping strategies used and the perceived effectiveness of those strategies in resolving the problem, may vary depending on the socioeconomic status of the individual.

First, the extremely poor group used a direct strategy when they had health or work problems and considered that strategy effective in resolving them. However, they tended to cope with economic problems using an evasive strategy.

Figures 3 and 5 also show that the moderately and not poor groups coped with health situations through direct strategies and, in the case of the moderately poor, educational situations were little associated with the use of strategies of self-blame or support-seeking.

\section{Conclusions}

To begin, research about stress and coping in marginalized populations or among the poor is very scarce. Not enough information is available to realize fully the type of situations to which the most underserved part of the population is exposed, in what important ways they experience stress and whether or not the way they handle their problems is effective in allowing them to resolve problematic situations, reduce their levels of stress and to begin to overcome poverty. The findings of the present study provide information which may inspire future directions of research which could deepen the understanding of this phenomenon.

Some of the most important findings derived from this study follow:

1. The type of situation reported as most stressful by subjects from the three socioeconomic groups studied are different, as are the strategies they used to cope with them.

2. The poorest group found itself most stressed by economic problems, while the moderately poor was most stressed by health problems and the not poor by family problems (although in the latter, the standardized residuals were not statistically significant).

3. Regarding direct strategies for coping with stress, it has been confirmed that although these are used by all three socioeconomic groups, the group that most often uses them is the not poor. The group who uses them least is the extremely poor.

4. As for the use of emotional coping strategies, it was observed that the extremely poor use them the most of the three groups and the not poor who use them the least.

5. Other strategies which were less used by the three groups include self-blame, denial or reductionism (falsely minimizing the problem) and "doing nothing."

6. One finding very relevant to the investigation is that the socioeconomic status of individuals produces differences in their coping styles depending on the stressful situation at hand. Although there exist some situations in which the extremely poor and the not poor rarely use any strategy other than direct, there are certainly other situations in which they largely employ other strategies. For example, in economically stressful situations, the extremely poor often turn to strategies of support-seeking, self-blame and reductionism. In the case of the not poor, while the percentage of use of direct strategies is much greater than among the extremely poor, it is also true that for the extremely poor, in environments such as work and family, the frequency in which other strategies are reported is high (although the standardized residuals show that the association is not significant).

7. The behavior of the moderately poor, as far as their coping styles, was different from what was expected, in that they used direct strategies less than the extremely poor and used emotional strategies more than the not poor (although the associations were not significant). As the strategies they used in distinct, stressful situations were researched, an inconsistent behavioral pattern in this group was observed. For example, they used direct strategies more than the extremely poor in health, education and family situations and also used them more than the not poor in health situations. Meanwhile, they used emotional coping strategies more than then extremely poor in the same situations (although the standardized residuals were not statistically significant).

8. Finally, it was concluded that the socioeconomic group to which individuals belong is also related with the type of feelings that stressful situations produce in them. Among the poorest subjects, the predominant feeling when faced with stressors was desperation, while among the not poor, it was anxiety. 
The reasons behind the differential use of coping strategies in different stressful situations reported by subjects remain unknown. In future research, it would be wise to incorporate other variables that could allow one to predict the probability of using one strategy or another in a given situation. Among these potential variables, consider the following examples: the sex of the subjects, the time for which subjects have been poor, whether or not there is a history of social mobility (social ascent or descent) in their family or in previous generations, whether or not the use of certain strategies in specific situations is related to personality traits such as drive for success, locus of control or how one views oneself, whether or not age is an important, contributing factor to the use of certain coping styles in different stages of life, as well as other sociodemographic variables (birth order, number of siblings, etc.).

However, it can be concluded that, although the nonpoor tend to use direct coping strategies to a greater extent, the poor groups also use this kind of strategies. This is encouraging, in view of the relation of this variable with other variables, such as achievement motivation, social competence, internal locus of control, etc., which are indispensable elements that enhance or increase the possibilities of improving people,s life conditions. Future research of this topic could include comparisons of groups that have experienced positive social mobility, in order to determine the predictive value of the use of direct stresscoping strategies.

\section{References}

Aldwin, C., \& Revenson, T.A. (1987). Does coping help? A reexamination of the relation between coping and mental health. Journal of Personality and Social Psychology, 53, 337-348.

Antonovsky, A. (1979). Health, stress, and coping. San Francisco: Jossey-Bass.

Balán, J., Blowing, H., \& Jelin, E. (1973). Migración, estructura ocupacional y movilidad social (el caso Monterrey). Mexico: Instituto de Investigaciones Sociales, UNAM.

Biblarz, T.J., \& Raftery, A.E. (1993). The effects of family disruption on social mobility. American Sociological Review, 58, 97-109.

Brown, G., Ni Bhrol-chain, M., \& Harris, T. (1975). Social class and psychiatric disturbance among women in an urban population. Sociology, 9, 225-2254.

Carver, C., Scheier, M., \& Weintraub, J. (1989). Assessing coping strategies: A theoretically based approach. Journal of Personality and Social Psychology, 56, 267-283.

Comisión Económica para América Latina e Instituto Nacional de Estadística, Geografía e Informática, CEPAL-INEGI, (1993). Magnitud y evolución de la pobreza en México, 1984-1992. Informe Metodológico, Instituto Nacional de Estadística, Geografía e Informática (INEGI).
Dohrenwend, B. (1973). Social status and stressful life events. Journal of Personality and Social Psychology, 28, 225-235.

Dohrenwend, B.P., \& Dohrenwend, B. (1969). Social status and psychological disorder. New York: Wiley.

Dohrenwend, B.S. (1970). Social class and stressful events. In E.H. Hare \& J.K. Wing (Eds.), Psychiatric Epidemiology (pp. 313319). New York: Oxford.

Dohrenwend, B.S., \& Dohrenwend, B.P. (1970). Class and race as status-related sources of stress. In S. Levine, \& N.A. Scotch (Eds.), Social Stress (pp. 111-140). Chicago: Aldine.

Dohrenwend, B.S., \& Dohrenwend, B.P. (1978). Some issues in research on stressful life events, The PERI life events scale. Journal of Health \& Social Behavior, 19, 205-229.

Folkman, S., \& Lazarus, R.S. (1980). An analysis of coping in a middle-aged community sample. Journal of Health and Social Behavior, 21, 219-239.

Folkman, S., Lazarus, R., Gruen, R., \& DeLongis, A. (1986). Appraisal, coping, health status, and psychological symptoms. Journal of Personality and Social Psychology, 50, 571-579.

Greenlee, R., \& Lantz, J. (1993). Family coping strategies and the rural Appalachian working poor. Contemporary Family Therapy: An International Journal, 15, 121-137.

Guttentag, M. Salasin, S. y Belle, D (eds) (1980). The mental health of women. New York: Academic Press.

Holmes, T.H., \& Rahe, R.H. (1967). The Social Readjustment Rating Scale. Journal of Psychosomatic Research, 11, 203218.

Johnson, J. H., \& Sarason, I. G. (1979). Moderator variables in life stress research. In I.G. Sarason \& C.D. Spielberger (Eds.), Stress and anxiety (Vol. 6, pp. 151-167). Washington, DC: Hemisphere.

Kaplan, H. (1970). Self-derogation and adjustment to recent life experiences. Archives of General Psychiatry, 22, 324-331.

Kessler, R., \& Cleary, P. (1980). Social class and psychological distress. American Sociological Review, 45, 463-478.

Kohn, M. L. (1977). Class and conformity: A study of values $\left(2^{\text {nd }}\right.$ ed.). Chicago: University of Chicago Press.

Kohn, M.L. (1968). Social class and schizophrenia: A critical review. In D. Rosenthal \& S. Kety (Eds.), The transmission of schziphrenia. Oxford: Pergammon.

Kohn, M.L. (1976). The interaction of social class and other factors in the etiology of schizophrenia. American Journal of Psychiatry, 133, 177-180.

Lazarus R.S. (1993) Coping theory and research: Past, present and future. Psychosomatic Medicine 55, 234-247.

Lazarus, R. S., \& Folkman, (1984). Stress, appraisal, and coping. New York: Guilford Press.

Liem, R., \& Liem, J. (1978). Social class and mental illness reconsidered: The role of economic stress and social support. Journal of Health and Social Behavior, 19, 139-156.

Lomnitz, L. (1998). Cómo sobreviven los marginados. México: Siglo XXI.

Meyer, A. (1957). Psychobiology: A science of man. Springfield, Illinois: C.C. Thomas. 
Pearlin, L. I., \& Schooler, C. (1978). The structure of coping. Journal of Health and Social Behavior, 19, 2-21.

Reese, H.W., \& Smyer, M.A. (1983). The dimensionalization of life events. In In E. J. Callahan \& K. A. McCluskey (Eds.), Life-Span developmental psychology, normative Life events (pp. 1-33). New York: Academic Press.

Rosenberg, M., \& Pearlin, L.I. (1978). Social class and self-esteem among children and adults. American Journal of Sociology, 84, 53-57.

Samaniego, V.C. (2001). Problemas comportamentales y sucesos de vida en niños de 4 y 5 años en Kiryat Hayovel, Jerusalem. In E. Saforcada (Ed.), El factor humano en la salud pública. Buenos Aires: Editorial Proa XXI.

Sandler, I.N., \& Ramsay, T. (1980). Dimensional analysis of children's stressful life events. American Journal of Community Psychology, 8, 285-302.
Thoits, P.A. (1982). Life stress, social support, and psychological vulnerability: Epidemiological considerations. Journal of Community Psychology, 10, 341-362.

Thoits, P.A. (1983). Dimensions of life events that influence psychological distress: An evaluation and synthesis of the literature. In H.R. Kaplan (Ed.), Psychosocial stress: Trends in theory and research (pp. 33-103). New York: Academic Press.

Thomson, E., McLanahan, S.S, \& Curtin, R.B. (1992). Family structure, gender, and parental socialization. Journal of Marriage and the Family, 54, 368-378.

Zaldivar, D.F. (1996). Conocimiento y dominio del estrés. La Habana: Editorial Científico-Técnica.

Received May, 25, 2006 Revision received August, 15, 2007 Accepted September, 1, 2007 